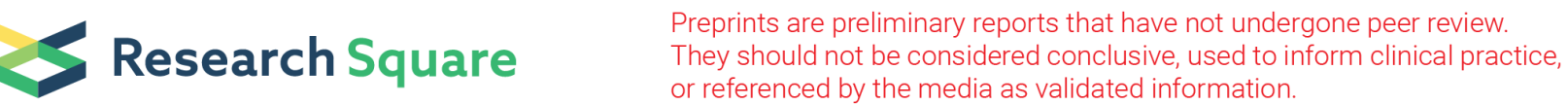

\section{Superhydrophobic Ceramic Hollow Fibre Membranes for Trapping Carbon Dioxide from Natural Gas Via the Membrane Contactor System}

Iltifat Hameed Saud

Basrah Engineering Technical College

Mohd Hafiz Dzarfan Othman ( $\sim$ hafiz@petroleum.utm.my )

Universiti Teknologi Malaysia https://orcid.org/0000-0002-5842-2447

Siti Khadijah Hubadillah

Universiti Technologi Malaysia

Mohd Haiqal Abd Aziz

Universiti Technologi Malaysia

Mohammad Arif Budiman Pauzan

Uneversiti Technologi Malaysia

Ahmad Fauzi Ismail

Uneversiti Technologi Malaysia

Juhana Jaafar

Uneversiti Technologi Malaysia

Mukhlis A Rahman

Universiti Technologi Malaysia

\section{Research Article}

Keywords: Kaolin hollow fibre membranes, FAS, superhydrophobicity, carbon dioxide separation

Posted Date: November 18th, 2020

DOI: https://doi.org/10.21203/rs.3.rs-106301/v1

License: (1) (1) This work is licensed under a Creative Commons Attribution 4.0 International License. Read Full License 


\section{Abstract}

The membrane contactor system is one of the most important technologies to trap $\mathrm{CO}_{2}$ from natural gas. To apply this technology, hollow fibre membranes with a superhydrophobic surface must be used. Three types of fluoroalkyl silane (FAS) molecules [C6, C8, C10] at different immersion times $(6,24,48,72 \mathrm{~h})$ were used to modify kaolin hollow fiber membrane into the superhydrophobic property to capture $\mathrm{CO}_{2}$ from natural gas via contacting gas-liquid system. The kaolin was chosen due to its abundantly available at an affordable price as well as a high amount of groups hydroxyl $(\mathrm{OH})$ in the surface which easily reacts with (FAS) during the grafting process. Superhydrophobicity was distinguished by Fourier transforms infrared (FTIR), scanning electron microscope (SEM), liquid entry pressure of water (LEPw) measurement, and contact angle (CA). The chosen superhydrophobic kaolin membrane was tested for carbon dioxide $\left(\mathrm{CO}_{2}\right)$ capture via the membrane contactor system. With increasing time of immersion, the hydrophobicity phenomena raised gradually until superhydrophobicity property was obtained. It was proved that the 48 hours was sufficient time to obtain the desired superhydrophobicity property to avoid wetting pores of the membranes. Besides, the perfect type of FAS for separation $\mathrm{CO}_{2}$ was $\mathrm{C} 8$ based on sufficient LEPw and contact angle. The reduction of $\mathrm{pH}$ was observed after testing the performance of using membrane contactor to separate $\mathrm{CO}_{2}$ by water as absorbent where $\mathrm{pH}$ value was reduced from 6.6 to 4.3 within one hour, which concludes that the success of the gas-liquid system to remove $\mathrm{CO}_{2}$ from natural gas.

\section{Highlights}

- The kaolin hollow fibre membranes were fabricated via the phase inversion process.

- Fluoroalkylsilanes (FAS) agents were used to improve the surface properties of kaolin membranes.

- The effect of hydrophobicity nature by using various FAS groups at different times has been investigated.

- The membrane contactor system has proven its effectiveness in $\mathrm{CO}_{2}$ separation by the pH values.

\section{Introduction}

The twenty-one century has observed a population increase and massive power consumption. Approximately 85 percent of global energy consumption comes from the use of petroleum-based solid and liquid petrol and diesel, natural gas, and coal [1]. Due to its efficiency, durability, and environmental benefits, natural gas is considered to be among the most desirable clean energy sources. As known, raw natural gas extracted from gas wells generally contain contaminants such as carbon dioxide $\left(\mathrm{CO}_{2}\right)$, that need to be extracted or reduced before transportation and delivery to natural gas supplies to (a) decrease the amount of gas transported in pipelines, (b) increase the heating value and decrease corrosion by natural gas transportation. Also, the contribution of $\left(\mathrm{CO}_{2}\right)$ to increasing global warming, as a result of harmful gas emissions from factories[2]. 
Consequently, it became necessary to find ways to reduce carbon dioxide emissions. Based on economic and environmental concerns, effective and acceptable $\mathrm{CO}_{2}$ separation technology with a low cost of production and energy usage must is implemented. Till now, several post-combustion capture gas separation technologies, such as (a) absorption (b) cryogenic distillation, (c) adsorption, and (d) membrane separation, were investigated.

The method of trapping $\mathrm{CO}_{2}$ which is nearest to commercialization is the mechanism of absorption by columns using amine solution, nevertheless does have different limits, like significant operational and capital costs, complicated production processes, and environmental pollution [3]. The membrane separation method is defined as a very important technology for sweetening natural gas and trapping $\mathrm{CO}_{2}$ from waste gases especially in remote locations where small footprints, durability, and much less maintenance are extremely coveted [4-6].

membrane contactor system (MC) is one of the most effective techniques of getting rid of pollutants like $\mathrm{CO}_{2}$, is a membrane system primarily used to contact two phases (gas mixture, water) to encourage the transfer of mass between these two phases, the separation of the gas by membranes is a process driven by pressure. This technology is selected as the best option of operational versatility, free flow of gas and liquid, high volume surface area, simple structure, easy scale-up, and modularity. Due to all these benefits, the membrane contactor is an excellent solution to separate $\mathrm{CO}_{2}$ from a mixture of gases [7]. The important criteria for the membrane contactor are the porous structure and hydrophobicity of the membrane surfaces, allowing fast penetration of gas into a liquid and preventing liquid from penetration into the pores[8]. Since membranes materials play a significant role in controlling the transfer of gas through the membrane, the membrane materials need to be appropriately chosen to meet the requirements of the gas/liquid contacting processes.

For industrial gas separations, many kinds of research about membrane contactors were increasingly investigated using polymeric materials such as polypropylene (PP)[9] and polysulfone (PS)[10] to separate $\mathrm{CO}_{2}$ from natural gas. Nevertheless, when implemented in high-pressure systems ( $>50$ bar), the application of polymer membrane is limited due to membrane deformation, plasticization, and continuous wetting throughout the procedure, which usually results in comparatively poor separation performance[11]. On the contrary, an inorganic membrane can provide specific high chemical and thermal stability and other advantages such as high mechanical properties, easy to begin preparing the asymmetric structure, and long lifetime and could have been prepared for the desired structure, such as dense or porous membranes, and attracted extensive study of ceramic membrane production and modification, include high temperatures, especially acidic or primary feed $[12,13]$.

The main materials used to prepare ceramic membranes are metal oxides such as alumina, zirconia, silica, and so on, which have main negative aspects, due to its high melting point $\left(2050^{\circ} \mathrm{C}\right)$ and high thermal coefficient, the manufacture of wide pores hollow fiber assistance for flux amplification is much more complicated with alumina, besides, these materials are very expensive, one $\mathrm{kg}$ for alumina almost 
\$250[14]. The alternative solution to using these materials used materials has low-price and the same properties such as dolomite [15], fly ash[16], kaolin[17, 18], apatite powder [19].

In this study, the material used is kaolin, which gains the preferred pore size for gas separation via membrane contactor. There are many reasons for using kaolin than other types of clays to fabricate hollow fiber membrane such as specific characteristics, the high ability for formation which can be used for many skills special for craftsmanship, can prepare variables with a wide range, use in catalytic amounts, easy to work and setup, moderate experimental conditions, yield and/or selectivity gains and low price around $\$ 15 / \mathrm{kg}[14,20]$.

Other than that, kaolin is hydrophilic and avoids fouling of membranes, this is due to the presence of $(\mathrm{OH})$ groups on the surface of these materials. This surface property prohibits their being used directly in the gas-absorption membrane system [21]. The suitable method to improve the properties of the surface by modifying it, to create the surface less adhesive and in doing so hydrophobic. Perfluoroalkylsilanes (PFAS) molecules are one of the various resources to modify the surfaces and making it non-adhesive, is a self-assembled monolayer (SAM) consisting of varying lengths of perfluorocarbon chains with a formula $\left(\mathrm{C}_{n} \mathrm{~F}_{2 n+1}-\mathrm{C}_{2} \mathrm{H}_{4} \mathrm{Si}\left(\mathrm{C}_{2} \mathrm{H}_{5} \mathrm{O}\right)_{3}\right)$, where $\mathrm{C}_{n} \mathrm{~F}_{2 n+1}$ it's a fluorocarbon chain and $\left(\mathrm{C}_{2} \mathrm{H}_{5} \mathrm{O}\right)$ it could be a methoxy or chlorine grouping.

Nevertheless, limited researches have been published on surface modification of the kaolin membrane to hydrophobic surfaces[22-24]. Abdulhameed et al. [22] examined the modification by FAS (C8) molecules of kaolin-alumina powders. Authors succeed in optimizing the wettability resistance of the membrane by achieving to high porosity to increase the gas permeation flux to $6.72 \times 10^{-5} \mathrm{~mol} / \mathrm{m}^{2} \mathrm{~Pa}^{1} \mathrm{~s}^{1}$ also, high contact angel $142^{\circ}$ by grafting C 8 to modify the membrane surface. The high-efficiency separation of $\mathrm{CO}_{2}$ almost $90 \%$ was obtained by using the modified ceramic membrane [23]. Hubadillah et al. applied Perfluorodecyltriethoxy- silane for the surface modification of kaolin hollow membranes in membrane distillation [24].

This study aims to fabricate a kaolin membrane with an improving structure to superhy-drophobicity towards a high-performance contacting method for liquid gas, which was also processed using the phase inversion-based extrusion method and sintered at $130{ }^{\square} \mathrm{C}$, following by grafting fluoroalkyl silane (FAS) at different immersion times, to investigate the effect of changing the time on membrane hydrophobicity. The performance of varying PFAS molecules grafted on the kaolin powders was evaluated and discussed using different analysis techniques (SEM, CA, LEPw, and FTIR). Furthermore, studying the efficiency of $\mathrm{CO}_{2}$ absorption through $\mathrm{pH}$ to be used in the membrane contactor system to capture $\mathrm{CO}_{2}$ from natural gas.

\section{Experimental}

\subsection{Material}


Powder clay of kaolin $\left(\mathrm{Al}_{2} \mathrm{O}_{3} 2 \mathrm{SiO}_{2} 2 \mathrm{H}_{2} \mathrm{O}\right)$ with the size of a particle between 2-3 $\mu \mathrm{m}$, the supplier is (KAOLIN SDN. BHD). 99.5\% of Methyl-2-pyrrolidone (NMP) from HPLC grade, Rathbone, and polyethersulfone (PESf) purchased from Amoco Chemicals were employed to prepare the suspension. Arlacel P135 (CRODA) was used as a solvent, for absorbent and coagulant was used tap water used as the liquid. Ethanol (Merck, Germany) was used for the surface grafting, fluoroalkylsilane (FASs) supplied from (Manchester Organics) at different chain bonds as cleared below:

- fluorooctyltriethoxysilane $\mathrm{C}_{6} \mathrm{~F}_{13} \mathrm{C}_{2} \mathrm{H}_{4} \mathrm{Si}\left(\mathrm{OC}_{2} \mathrm{H}_{5}\right)_{3}-\mathrm{C} 6$

- fluoridecyltriethoxysilane $\mathrm{C}_{8} \mathrm{~F}_{17} \mathrm{C}_{2} \mathrm{H}_{4} \mathrm{Si}\left(\mathrm{OC}_{2} \mathrm{H}_{5}\right)_{3}$ - $\mathrm{C} 8$

- fluorododecyltriethoxysilane $\mathrm{C}_{10} \mathrm{~F}_{21} \mathrm{C}_{2} \mathrm{H}_{4} \mathrm{Si}\left(\mathrm{OC}_{2} \mathrm{H}_{5}\right)_{3}$ - $\mathrm{C} 10$

\subsection{Preparation of spinning dope}

The hollow-fibre Kaolin membrane was processed to use an extrusion/sintering technique based on inversion. First of all, materials were weighed (kaolin, NMP, PESF, Arlacel). First, 54 wt.\% of NMP solvent and Arlacel $1 \mathrm{wt}$. \% mixed and stirring to dissolve these materials. Then added kaolin $40 \mathrm{wt}$. \%, and gradually blended for homogeneous mixing with continuous blending. The dispersal was rolled for two days in planetary ball mill NQM-2 to ensure good dispersion of kaolin powder. After that, applied about 5 wt. \% of a specific quantity of PESf. After suspension and a further two days of milling began. A pump was used to get rid of the bubbles until did not exist to prepare a spinning suspension, so had discharged at room temperature for ten minutes in the beginning and then used the pump.

The next step of spinning the ceramic hollow fiber, the precursor degassed, and the dope suspension moved it to the stainless-steel syringes extruded, is a tube in orifice spinneret with an external diameter of approximately $3 \mathrm{~mm}$ and an internal diameter of $1.5 \mathrm{~mm}$ utilizing syringe pumps (PHD 2000, Harvard Apparatus) at a steady speed of $10 \mathrm{ml} / \mathrm{min}$ and a temperature of $25^{\circ} \mathrm{C}$ with $10 \mathrm{ml} / \mathrm{min}$ bore fluid (tap water) as the internal coagulant, bath to allow a complete phase inversion process. The air gap was maintained constant at $5 \mathrm{~cm}$ to run the extrusion process easily and efficiently because greater air gap distance enabled the dope suspension flow to become unstable due to the high viscosity of the dope. The hollow fiber precursor was held in water to extract the residual solvents for 24 hours and then washed with water. The green fibres would then be cut to $25 \mathrm{~cm}$ and dried at ambient temperature for 2-3 days with good ventilation.

\subsection{Sintering process}

The sintering process was used to integrate the precursor of a strong kaolin hollow fiber by rising-degree of heat. To sinter the precursor, the tubular furnace was used (XY-1700 MAGNA) at a high-temperature. At first, the precursors were sintered at room temperature, then the temperature kept increasing to $600{ }^{\circ} \mathrm{C}$ at a rate of $2{ }^{\circ} \mathrm{C} / \mathrm{min}$ and maintained for two hours to get rid of the remaining liquid compounds, the 
residual organic components, and the dispersant. Then, increase the temperature to a specified temperature of $1300^{\circ} \mathrm{C}$ at a rate of $5^{\circ} \mathrm{C} / \mathrm{min}$ and set for 4 hours. The last step is to cool the furnace at a rate of $5{ }^{\circ} \mathrm{C} / \mathrm{min}$ down to ambient temperature.

\subsection{Improvement superhydrophobicity of kaolin hollow fiber membrane by FAS}

The surface of kaolin hollow fibre membranes can modify by using many materials to improve the characterization of the surface. Three types of fluoroalkyl silane chain [(C6), (C8), (C10)] were grafted to the kaolin membrane surface. This modification is produced by the reaction of the modifying compound between two groups (hydroxyl which available at membrane) and the groups of ethoxy (O-Et) contained in components of the organosilane (silane groups at FAS compounds) as shown in Fig. 1. To complete the grafting process, the hydrolyzes procedure should be applied by putting the membrane in a flask and filling it with (200) $\mathrm{ml}$ of ethanol and the rest with water to rebuild the $\mathrm{OH}$ group that lost during the sintering process and then left the membrane for one evening, after that wash it with tap water and drying at a temperature of hundred Celsius for one day. Then cut the membrane lengthwise $(10 \mathrm{~cm})$ and immersed in $0.02 \mathrm{~mol} / \mathrm{L}$ of FAS solution using ethanol (0.98) $\mathrm{ml}$ at room temperature for $(6,24,48$, and $72 \mathrm{~h}$ ) to allow proper interaction. Finally, the grafted membranes were cleaned with distilled water and dried all night in an oven at $100^{\circ} \mathrm{C}$. As cleared from Fig.1, the effect of hydrophobization was very successful to change the properties of the surfaces as the contact angle changes from $20^{\circ}$ (hydrophilic) to $160^{\circ}$ (superhydrophobic).

\subsection{Membrane characterization}

\subsubsection{Contact angle measurement (CA)}

Is an effective way to identify the conversion of water droplet size after modification surfaces from hydrophilicity to superhydrophobicity. This technique is applied by measuring the angle of droplet water attached to the modified membrane surfaces, to clarify the changes which occurred due to the grafting process by (CA, OCA 15EC Data physics, Germany), using sessile drop property. With a very highresolution camera, it possible to obtain highly accurate results by placed points of distilled water on the different positions of an outside surface to calculate the average of results to reduce errors that occur during the test.

\subsubsection{Liquid entry pressure of water (LEPw)}

To identify the gas permeation of the kaolin membrane, the liquid entry pressure of water (LEPw) technique applied. A diaphragm pump was used to inject distilled water into the lumen sides of the 
hollow fibre membranes. The pressure started increasing at a rate of 0.5 bar, and the pressure was registered as LEPw at which the first water droplets appear on the shield outer side of the kaolin hollow fibre.

\subsubsection{Scanning electron microscope (SEM)}

A scanning electron microscope (SEM) of the kaolin membrane was applied with the use of (SEM, Hitachi TM3000) advice. This technique Had been used to examine membrane morphology changes for kaolin surfaces and section crossings during the grafting process. To create a smoother cross-section surface, the hollow fibres were carefully cut. Before processing, the split fibers were put on a disc for spraying with such a simple gold film. At different magnifications, the SEM micrographs had been obtained of the cross-sections and the shell side surfaces

\subsubsection{Fourier-transform infrared (FT-IR)}

Fourier-transform infrared (FT-IR) spectra were necessarily using a spectrophotometer (IR tracer 100 Shimadzu) fitted with a singular-reflection PIKE Horizontally Attenuated Total wavelength adapter. More than 1000 scans over a spectrum of $600-4000 \mathrm{~cm}^{-1}$ were averaged with FTIR spectra. Membranes were dried at room temperature in a vacuum oven at $40^{\circ} \mathrm{C}$ after testing. As well as characterizing the degradation process of the fluorocarbon chains at high temperatures, the FT-MIR technique was used to estimate the efficacy of the grafting operation.

\subsubsection{Membrane contactor setup}

In membrane contactor setup, kaolin hollow fibre membranes with a length of $10 \mathrm{~cm}$ were arranged into a tube made from stainless steel with a diameter $(1 \mathrm{~cm})$. Before starting the operation of this process, especially before pumping, the flow rate of $\mathrm{CO}_{2}$ should be ascertained, and this through the control unit (Cole-Parmer model 75211-15). Pressure should also be maintained by pressure gauge gas. Gas pressure should be less than liquid pressure (for gas 1 bar and liquid 1.2 bars) to avoid formation gas bubbling into liquid. After making sure to adjust these requirements, the operation of the membrane contactor begins. Through the beginning flow both of the water and mixture of gases in opposite directions, absorbing $\mathrm{CO}_{2}$ starts via water from the gas mixture through the porous membrane and due to the superhydrophobic nature of the kaolin membrane surface after grafting, the droplet of water was carried the $\mathrm{CO}_{2}$ and go outside of membrane to collect in the special tank for this acidic solution as shown in Fig. 2.

\section{Results And Discussion}

\subsection{Properties of Kaolin Hollow Fibre Membranes}




\subsubsection{Hydrophobicity properties measurement}

Determining the efficacy of the kaolin membrane grafting procedure, the membrane's wettability characteristics were assessed in terms of the contact angle value. Figure 3 illustrates the contact angles (CA) for the membrane of both original and grafted with three types of FAS agents $(\mathrm{C} 6, \mathrm{C} 8$, and $\mathrm{C} 10)$ at different times.

Figure 3 (a) demonstrates a pristine kaolin membrane called a hydrophilic membrane. This appears to mean that the contact angle $(0 \otimes<\theta<90 \mathrm{Q})$, as well as the surface of the membrane, have a wetting phenomenon and this effect has an impact on the efficiency of the $\mathrm{CO}_{2}$ separation due to the hydroxyl content of the membrane surfaces. A research carried out by [25] showed that the pristine membrane was super hydrophilic without any changes when the contact angle was equal to zero or hydrophilic when the contact angle was less than 90囚.

After the grafting process, the contact angle values of all samples powder exceeded $90^{\square}$, this verified that the grafted kaolin membrane had a hydrophobicity. After six hours of grafting, the nature of C6 and C8 were changed to ultra-hydrophobic with a contact angle around $131^{\square}$ but $\mathrm{C} 10$ still just hydrophobic. With increasing time of grafting to 24 hours, the surface membrane continues to change more to ultrahydrophobic with contact angle $142^{\square}, 137^{\square}$ for $\mathrm{C} 8$, and $\mathrm{C} 6$, respectively but for $\mathrm{C} 10$ around $128^{\square}$. At $48 \mathrm{~h}$ for $\mathrm{C} 6$, the contact angle around $150^{\square}$, compared to $\mathrm{C} 8$ the contact angle equal $162^{\natural}$, and $\mathrm{C} 10$ around $138^{\square}$ as shown in Fig. 3(b).

When the time of grafting increased to $72 \mathrm{~h}$ the behavior of the membrane changed to be as superhydrophobic with a contact angle of more than $150^{\square}$ and more than $160^{\square}$ for C6 and C8 respectively, but for membrane grafted by $\mathrm{C} 10$ at this time, it was obtained ultra-hydrophobic surface. This concludes, can get the superhydrophobicity at $48 \mathrm{~h}$ for $\mathrm{C} 8$ agent because it is the first grafted kaolin membrane that has a phenomenon of superhydrophobicity due to the highest value of $\mathrm{CA}$, that is in excellent accordance with the results of J. Lu's work [26]. Some factors make fluorodecyltriethoxysilane-C8 a perfect type to get the superhydrophobic nature to the kaolin hollow fiber membrane. At first, factor the surface density and particle area density at the kaolin membrane for $\mathrm{C} 8$ highest among the other kinds of FAS. As a result of this, the contact angle was also highest. Also, both the roughness surface and the density reached the highest value, which leads to making the contact angle largest, and this point was the main reason for the various contact angle between the samples of the FAS agent. Furthermore, C8 molecules had longer hydrophilic chains which covered a much higher surface.

So, there is a correlation between the conditions of modification (time and kind of FAS agent) which have a significant influence on the resulting degree of hydrophobicity. This interpretation is in good accordance with the work of the research groups Lee \& Hoon [27] and [28] who also establish that increasing the grafting time results in increased water contact angle value, which has also been obtained from this study. 


\subsubsection{Pressure resistance measurement}

To assess the wettability resistance of the membrane, Liquid entry pressure of water ( $L E P W)$ was carried out for kaolin membranes after $(6,24,48,72 \mathrm{~h})$ of modification (Fig. 4). In the membrane contactor systems, wetting resistance is critical as the membranes with higher LEPw will avoid the liquid from penetration into pores until the pressure difference is surpassed. As illustrated the best kind of grafted membrane it was grafting with agent $\mathrm{C} 8$, which exposure for 48 hours because the pressure at this point was ( 2 bars) and this means, at this point of pressure, the membrane has excellent features that prevent water penetration through the outside surface of the kaolin membrane inside the lumen. These findings are also in sync with the results presented by [29]. This high pressure is correlated with the high contact angle $\sim 160^{\square}$, which means if the contact angle increases, the $L E P W$ value also increases and vice versa, providing a good air pocket that produces sufficient air pockets on the membrane surface, and improves water penetration resistance. Besides, $L E P W$ is increased by decreasing the diameter of the membrane pores, as indicated by [30].

The less value of $\angle E P W$ it was for $\mathrm{C} 10$, and this due to the different structures of grafting molecules. But as clear from the figure after increasing grafting time more than $48 \mathrm{~h}$ the value of $L E P W$ decreased, there are several reasons for this decline, such as the amount of hydroxyl group lowering with increasing the grafting time, as a result of a long time of interaction between $\mathrm{OH}$ group on kaolin surface and silica group from FAS agent which lead to losing the amount of $\mathrm{OH}$ in contrast previous period time of grating, when the amount of $\mathrm{OH}$ was plentiful. And $\mathrm{CO}_{2}$ absorption of membrane fluxes decreased with increased FAS coating period, in addition to increasing the grafting time, the gas permeation was decreased. This concludes the pore size of the membrane is more significant than the initial time, and the value of $L E P W$ is reduced. At last, the pores of the membrane wetting and made the quality of the membrane low. Studies conducted by Rácz et al. [31] have reported the factors which affect the value of hydrophobicity and pressure resistance of water and the major relation between these two measurements.

\subsubsection{Morphology of the fabricated membranes}

Figure 5 shows the scanning electron microscope (SEM) to investigate the microstructure of both the outer layer and the cross-section of the kaolin membranes for pristine and grafted membranes with a variety for FAS agents at $48 \mathrm{~h}$ which selected as the appropriate time to achieve superhydrophobicity.

A high porosity sponge-like structure emanating from the internal surface of the pristine kaolin fiber could be obtained based on the SEM cross-sectional images as showed in Fig. 5 (A1, A2). The inner diameter of the kaolin membrane is $1.82 \mathrm{~mm}$ and the thickness of the wall of $1.35 \mathrm{~mm}$, asymmetric structure of the membrane, and much of the sponge-like parts on the inside of the hollow fibre membrane rather than the outside surfaces could notice. However, because the size of pores is not homogeneous, the removal efficiency for this membrane is limited, so it is required for membrane support. This finding was also following the earlier research of Abdulhameed et al., the authors have already reported the reason for the presence of a sponge-like formation is due to the gradual precipitation during contact with the dope 
suspension the non-solvent (water), the infrequent shape of kaolin, which looked like flakes that effect exchanged between water and solvent, then lead to the formation sponge structure[18]. It is worth to mention to study stated by Hubadillah et al., they have observed the perfect particle content to use for membrane manufacturing if the kaolin content from ceramic suspensions $40 \%$, for several reasons such as high viscosity, which decreases the creation of finger-like voids and creates sponge structure, [32], where the reduction in kaolin content below $35-40 \%$ leads in an extremely low viscosity and thus a reduced formation of a sponge-like structure, which was the same behavior found in this study.

After the grafting process, some changes occurred in the microstructure of membranes. Figu (5 B, C, D) show the grafted membranes with three types of FAS $(\mathrm{C6}, \mathrm{C} 8, \mathrm{C} 10)$ respectively at immersion time (48 hours). As mentioned in Fig. (5 B1-D1). There is a slight gradual increase in dimensions (inner diameter and wall thicknesses), even the pore size of the kaolin membrane showed significant improvement at the sponge-like structure, due to the use of the FAS agent. In Fig. (5 B2) which used C6 molecules, the size of pores is closer to more than $\mathrm{A} 2$ due to the reaction of $\mathrm{OH}$ groups on membrane surfaces with silane groups to transform surface to hydrophobic.

Figure (5C) represented the grafted kaolin membrane by the $\mathrm{C} 8$ agent. The inner diameter and wall thickness be $(1.89 \mathrm{~mm}$ and $1.42 \mathrm{~mm})$, respectively. the cross-section of the pore becomes more closed, and the surface denser as shown in Fig. $(5 \mathrm{C} 2, \mathrm{C} 3)$. It means that the membrane surface is fully covered with fluoroalkyl silane and the top layer was created by the grafted $\mathrm{C} 8$, which has a shallow thickness $(1,42 \mathrm{~mm})$ due to the polymer binder in the precursor fibres. It is worth noting that the obtained results in this study are in line with the results found by [33].

Figure (5D) shows the grafting of FAS agent-C10 at 48 hours. The inner diameter increased to $(2.8 \mathrm{~mm})$ and the wall thickness to $(1.62 \mathrm{~mm})$. It implies the interaction FAS agent bonds with inner diameter and thickness were directly proportional. There are no big differences between the outer surfaces for all different grafting membranes, even non grafted ones, as shown in figure (8A-D) which means the FAS is affected in the inner more than the outer surface.

\subsubsection{Fourier Transform Infrared (FIR) analysis}

To ensure the effectiveness of the grafting and its efficacy Fourier transform infrared, (FTIR) analysis has been applied. Figure 6 presents FTIR spectra of pristine and three types of FAS agent (C6, C8, and C10) grafted on kaolin membranes at $48 \mathrm{~h}$, which it was selected as the best time to get superhydrophobic phenomena. Un grafted membrane starts at band $2851 \mathrm{~cm}^{-1}$ as mention in Fig. 6 , since the pristine kaolin surfaces membranes are saturated with hydroxy groups which are the main reason why kaolin acts as hydrophilic. After the membrane modification, the spectra changed to $2880 \mathrm{~cm}^{-1}$ correlates to the $\mathrm{OH}$ stretching mode of the adsorbed water. The relevant vibration bands perfluorinated chains were observed at the frequency range $1244-1030 \mathrm{~cm}^{-1}$ [34]. The Si-O bond vibration was observed on frequency $1119 \mathrm{~cm}^{-1}$, this can refer to the presence of the Si-O- $\mathrm{X}(\mathrm{X}=$ kaolin) bond as a result of the chemical $\mathrm{Si}\left(\mathrm{OCH}_{2} \mathrm{CH}_{3}\right)_{3}$ methyl groups and the accessible hydroxyl groups on the surface of the powder 
content [30]. At $\left(1084 \mathrm{~cm}^{-1}\right)$ was observed Si-OH band, this band was increased with increasing grafting time, it was clear the $\mathrm{C} 10$ has the highest intensity for this band. For Si-O-C stretching and deformation, vibrations were located at bonds between $840 \mathrm{~cm}^{-1}$, this result is mostly in alignment with Jeong work [35]. The peak at around $721 \mathrm{~cm}^{-1}$ was located in all samples and identical to $\mathrm{Si}-\mathrm{C}$ stretching motion. At concluding of the FTIR analysis for these grafted membranes, as clear the reaction between Kaolin and FAS agent was occurred for all samples by creating different bonds at variety peaks, and the highest intensity value bond was recorded to $\mathrm{C} 10$ followed $\mathrm{C} 8$, then the other agents and lowest one was the pristine due to containing $\mathrm{OH}$ group.

\subsection{Performance of $\mathrm{CO}_{2}$ absorption}

The absorption $\mathrm{CO}_{2}$ performance should be estimated to ensure the efficiency of material used to complete the process of $\mathrm{CO}_{2}$ stripping in the membrane contactor system through a mix of gases $\left(\mathrm{CH}_{4}\right.$, $\mathrm{CO}_{2}$ ) and nonsolvent (water) as solute gas and absorbent gas respectively. By presenting the gas mixture pumped through the lumen side, the testing was conducted out and water was pumped through the shell side at the same time in the mode of counter-current. $\mathrm{pH}$ values as a function of different periods for kaolin membrane grafted by $\mathrm{C} 8$, which was selected as the best type of FAS to provide superhydrophobic membrane at $48 \mathrm{~h}$ as shown in Fig. 7.

Figure 7 shows the first point for reverse osmosis (RO) water which has a pH of around 6.6, this normal value for $\mathrm{RO}$ water, which means it is almost free from $\mathrm{CO}_{2}$. Ten minutes later, the value of $\mathrm{pH}$ decreases to 5.5 , and with increasing the time of using a membrane contactor system, the value of pH gradually goes down to reach 4.3 after one hour. The reason for decrease $\mathrm{pH}$ with increasing the absorbing time, because the amount of $\mathrm{CO}_{2}$ absorbed was increased and led to a decrease in the amount of $\mathrm{CO}_{2}$ in a mixture of gases then made it almost pure from this impurity, and makes the solution more acidic, for that $\mathrm{pH}$ value decrease. These results are also in line with findings presented by Sedghi et al. [36], the authors modified the polyethylene hollow fibers to use in the membrane contactors, they noticed that the chemical degradation of the membranes appears to be less significant in the presence of $\mathrm{CO} 2$, and this lead to a reduction of the $\mathrm{pH}$ of the loaded MEA solutions. In another study carried out by[37], in their studies, due to $\mathrm{CO}_{2}$ absorption, the most significant $\mathrm{pH}$ decrease from 6.01 to 3.69 was obtained to separate $\mathrm{CH}_{4}$ and $\mathrm{CO}_{2}$ utilizing membrane contactors. Also, should mention, with increasing time of separation, the membrane was wetted and led to a decrease in the efficiency of separation. Therefore, should be maintained the kaolin membrane from time to time to prevent the wetting membrane. This concludes the success of gas-liquid membrane contactor to absorb carbon dioxide by using water as an absorber and all this happen due to using membrane grafted by $\mathrm{C} 8$.

\section{Conclusion}


The kaolin powder was effectively modified from hydrophilic to superhydrophobic by using the extrusionbased phase-inversion process. Coating the kaolin surface by [(C6), (C8), (C10)] was successfully applied to improve wetting resistance and separation performance in the gas-liquid contactor system for efficient $\mathrm{CO}_{2}$ removal. The mode of anchoring FAS molecules depends on the FAS type and the time of grafting.

The grafting time is most important for obtaining the highest hydrophobicity for ceramic materials; a hydrophobic increase is, therefore observed by increasing the grafting time. By contact angle analysis the highest angle obtained was $160^{\natural}$ for $\mathrm{C} 8$ at $48 \mathrm{~h}$, which means the superhydrophobic phenomenon was achieved. SEM examines the microstructure of the membrane, the modifications observed on the inside of the hollow fibre membrane rather than the outside surfaces, due to the impact on the surface of the FAS bonds. The higher wettability resistance has occurred, when getting $L E P W$ value 2 bars. In conclusion, $48 \mathrm{~h}$ was appropriate to avoid the wetting of membrane pores, and the best type of FAS was being used for $\mathrm{CO}_{2}$ separation from the gas mixture was $\mathrm{C} 8$. Further studies are to fabricate superhydrophobic surfaces that have the long-term thermal and chemical stability of the super-hydrophobic membrane. Also, used materials can get the super-hydrophobicity at a shorter time and can prevent wetting membrane, in order implemented in MC practice at large-scale.

\section{List Of Abbreviations}

C6 fluorooctyltriethoxysilane $\mathrm{C}_{6} \mathrm{~F}_{13} \mathrm{C}_{2} \mathrm{H}_{4} \mathrm{Si}\left(\mathrm{OC}_{2} \mathrm{H}_{5}\right)_{3}$

C8 fluoridecyltriethoxysilane $\mathrm{C}_{8} \mathrm{~F}_{17} \mathrm{C}_{2} \mathrm{H}_{4} \mathrm{Si}\left(\mathrm{OC}_{2} \mathrm{H}_{5}\right)_{3}$

C10 fluorododecyltriethoxysilane $\mathrm{C}_{10} \mathrm{~F}_{21} \mathrm{C}_{2} \mathrm{H}_{4} \mathrm{Si}\left(\mathrm{OC}_{2} \mathrm{H}_{5}\right)_{3}$

FAS fluoroalkylsilans

MC Membrane contactor

O-Et groups of ethoxy

SEM Scanning electron microscope

FTIR Fourier Transform Infrared

CA Contact Angle

LEPw liquid entry pressure of water

RO Reverse osmosis

pH Acid-base scale

\section{Declarations}




\section{Acknowledgment}

The authors gratefully acknowledge the financial supports from the Ministry of Higher Education Malaysia under the Malaysia Research University Network (MRUN) Grant (Project Number:

R.J130000.7809.4L867) and Fundamental Research Grant Scheme (Project Number:

R.J130000.7809.5F161), and Universiti Teknologi Malaysia under the UTM Transdisciplinary Research Grant (Project number: Q.J130000.3509.05G75) and Collaborative Research Grant (CRG) (Project number: Q.J130000.2409.08G29).

\section{References}

1. Nanda S, Mohammad J, Reddy SN, Kozinski JA, Dalai AK (2014) Pathways of lignocellulosic biomass conversion to renewable fuels. Biomass Convers Biorefinery 4:157-191

2. Liu C, Yao Z, Wang K, Zheng X, Li B (2019) Net ecosystem carbon and greenhouse gas budgets in fiber and cereal cropping systems. Sci Total Environ 647:895-904

3. Ghasem N, Al-Marzouqi M, Duidar A (2012) Effect of PVDF concentration on the morphology and performance of hollow fiber membrane employed as gas-liquid membrane contactor for $\mathrm{CO} 2$ absorption. Sep Purif Technol 98:174-185

4. Belmabkhout Y, Bhatt PM, Adil K, Pillai RS, Cadiau A, Shkurenko A, Maurin G, Liu G, Koros WJ, Eddaoudi M (2018) Natural gas upgrading using a fluorinated MOF with tuned $\mathrm{H} 2 \mathrm{~S}$ and $\mathrm{CO} 2$ adsorption selectivity. Nat Energy 3:1059-1066

5. Liu G, Li N, Miller SJ, Kim D, Yi S, Labreche Y, Koros WJ (2016) Molecularly designed stabilized asymmetric hollow fiber membranes for aggressive natural gas separation. Angew Chemie 128:13958-13962

6. He X, Hägg M-B (2011) Hollow fiber carbon membranes: Investigations for CO2 capture. J Memb Sci 378:1-9

7. Ismail AF, Khulbe KC, Matsuura T, Application of Gas Separation Membranes, in: Gas Sep. Membr., Springer (2015) pp. 241-287

8. Aroon MA, Ismail AF, Matsuura T, Montazer-Rahmati MM (2010) Performance studies of mixed matrix membranes for gas separation: A review, Sep. Purif Technol 75:229-242

9. Nakhjiri AT, Heydarinasab A, Bakhtiari O, Mohammadi T (2018) Experimental investigation and mathematical modeling of $\mathrm{CO}_{2}$ sequestration from $\mathrm{CO}_{2} / \mathrm{CH}_{4}$ gaseous mixture using MEA and TEA aqueous absorbents through polypropylene hollow fiber membrane contactor. J Memb Sci 565:1-13

10. Roslan RA, Lau WJ, Zulhairun AK, Goh PS, Ismail AF (2020) Improving $\mathrm{CO}_{2} / \mathrm{CH}_{4}$ and $\mathrm{O}$ 2/N 2 separation by using surface-modified polysulfone hollow fiber membranes. J Polym Res 27:1-14

11. Budd PM, Msayib KJ, Tattershall CE, Ghanem BS, Reynolds KJ, McKeown NB, Fritsch D (2005) Gas separation membranes from polymers of intrinsic microporosity. J Memb Sci 251:263-269 
12. Faiz R, Fallanza M, Ortiz I, Li K (2013) Separation of olefin/paraffin gas mixtures using ceramic hollow fiber membrane contactors. Ind Eng Chem Res 52:7918-7929

13. Al-Marzouqi MH, El-Naas MH, Marzouk SAM, Al-Zarooni MA, Abdullatif N, Faiz R (2008) Modeling of CO2 absorption in membrane contactors. Sep Purif Technol 59:286-293

14. Johnson EBG, Arshad SE, Hydrothermally synthesized zeolites based on kaolinite: A review, Appl. Clay Sci. 97-98 (2014) 215-221

15. Saffaj N, Persin M, Younsi SA, Albizane A, Cretin M, Larbot A (2006) Elaboration and characterization of microfiltration and ultrafiltration membranes deposited on raw support prepared from natural Moroccan clay: application to filtration of solution containing dyes and salts. Appl Clay Sci 31:110119

16. Zou D, Qiu M, Chen X, Drioli E, Fan Y (2019) One step co-sintering process for low-cost fly ash based ceramic microfiltration membrane in oil-in-water emulsion treatment. Sep Purif Technol 210:511520

17. Aissat M, Hamouda S, Bettahar N, Tarboush BJ, Bahmani A, Characterization and application of ceramic membranes prepared from Algerian kaolin, Cerâmica. 65 (2019) 554-561

18. Abdulhameed MA, Othman MHD, Ismail AF, Matsuura T, Harun Z, Rahman MA, Puteh MH, Jaafar J (2017) Preparation and characterisation of inexpensive porous kaolin hollow fibre as ceramic membrane supports for gas separation application. J Aust Ceram Soc 53:645-655

19. Sahoo GC, Halder R, Jedidi I, Oun A, Nasri H, Roychoudhurry P, Majumdar S, Bandyopadhyay S (2016) R. Ben Amar, Preparation and characterization of microfiltration apatite membrane over low cost clay-alumina support for decolorization of dye solution, Desalin. Water Treat 57:27700-27709

20. Hubadillah SK, Othman MHD, Matsuura T, Ismail AF, Rahman MA, Harun Z, Jaafar J, Nomura M (2018) Fabrications and applications of low cost ceramic membrane from kaolin: A comprehensive review. Ceram Int 44:4538-4560

21. Mittal P, Jana S, Mohanty K (2011) Synthesis of low-cost hydrophilic ceramic-polymeric composite membrane for treatment of oily wastewater. Desalination 282:54-62

22. Abdulhameed MA, Othman MHD, Ismail AF, Matsuura T, Harun Z, Rahman MA, Puteh MH, Jaafar J, Rezaei M, Hubadillah SK (2017) Carbon dioxide capture using a superhydrophobic ceramic hollow fibre membrane for gas-liquid contacting process. J Clean Prod 140:1731-1738

23. An L, Yu X, Yang J, Tu ST, Yan J (2015) $\mathrm{CO}_{2}$ Capture using a Superhydrophobic Ceramic Membrane Contactor. Energy Procedia 75:2287-2292

24. Hubadillah SK, Othman MHD, Ismail AF, Rahman MA, Jaafar J (2019) A low cost hydrophobic kaolin hollow fiber membrane (h-KHFM) for arsenic removal from aqueous solution via direct contact membrane distillation. Sep Purif Technol 214:31-39

25. Himma NF, Prasetya N, Anisah S, Wenten IG (2019) Superhydrophobic membrane: progress in preparation and its separation properties. Rev Chem Eng 35:211-238 
26. Lu J, Yu Y, Zhou J, Song L, Hu X, Larbot A (2009) Applied Surface Science FAS grafted superhydrophobic ceramic membrane 255:9092-9099

27. Lee HJ, Hoon J (2016) Effect of hydrophobic modi fi cation on carbon dioxide absorption using porous alumina $\left(\mathrm{Al}_{2} \mathrm{O}_{3}\right)$ hollow fi ber membrane contactor. J Memb Sci 518:79-87

28. Kujawa J, Kujawski W, Koter S, Jarzynka K, Rozicka A, Bajda K, Cerneaux S, Persin M, Larbot A (2013) Membrane distillation properties of TiO2 ceramic membranes modified by perfluoroalkylsilanes, Desalin. Water Treat 51:1352-1361

29. Hubadillah SK, Ha M, Othman D, Ismail AF, Rahman MA, Separation and Puri fi cation Technology A low cost hydrophobic kaolin hollow fi ber membrane (h-KHFM) for arsenic removal from aqueous solution via direct contact membrane distillation, (2018)

30. Kujawa J, Cerneaux S, Kujawski W (2014) Investigation of the stability of metal oxide powders and ceramic membranes grafted by perfluoroalkylsilanes, Colloids Surfaces A Physicochem. Eng Asp 443:109-117

31. Rácz G, Kerker S, Kovács Z, Vatai G, Ebrahimi M, Czermak P (2014) Theoretical and experimental approaches of liquid entry pressure determination in membrane distillation processes. Period Polytech Chem Eng 58:81-91

32. Hubadillah SK, Othman MHD, Rahman MA, Ismail AF, Jaafar J (2020) Preparation and characterization of inexpensive kaolin hollow fibre membrane (KHFM) prepared using phase inversion/sintering technique for the efficient separation of real oily wastewater. Arab $\mathrm{J}$ Chem 13:2349-2367

33. Abdulhameed MA, Othman MHD, Al Joda HNA, Ismail AF, Matsuura T, Harun Z, Rahman MA, Puteh $\mathrm{MH}$, Jaafar J (2017) Fabrication and characterization of affordable hydrophobic ceramic hollow fibre membrane for contacting processes. J Adv Ceram 6:330-340

34. Fang H, Gao JF, Wang HT, Chen CS (2012) Hydrophobic porous alumina hollow fiber for water desalination via membrane distillation process. J Memb Sci 403:41-46

35. Jeong HJ, Kim DK, Lee SB, Kwon SH, Kadono K (2001) Preparation of water-repellent glass by sol-gel process using perfluoroalkylsilane and tetraethoxysilane. J Colloid Interface Sci 235:130-134

36. Sedghi SM, Brisson J, Rodrigue D, Iliuta MC (2011) Chemical alteration of LDPE hollow fibers exposed to monoethanolamine solutions used as absorbent for $\mathrm{CO}_{2}$ capture process. Sep Purif Technol 80:338-344

37. Hidalgo D, Sanz-Bedate S, Martín-Marroquín JM, Castro J, Antolín G (2020) Selective separation of $\mathrm{CH}_{4}$ and $\mathrm{CO}_{2}$ using membrane contactors. Renew Energy 150:935-942

\section{Figures}




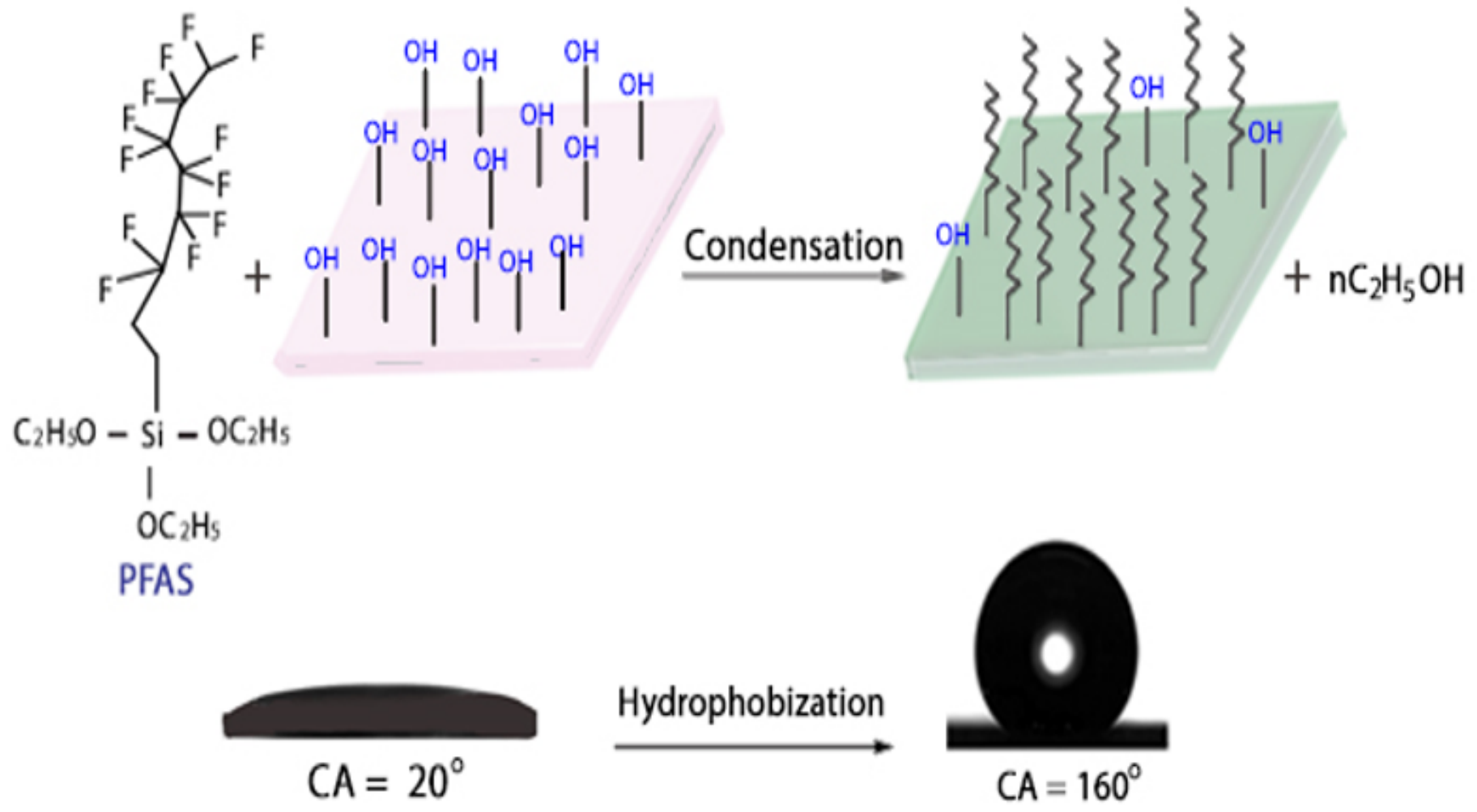

Figure 1

Scheme of the grafting process by PFAS compounds.

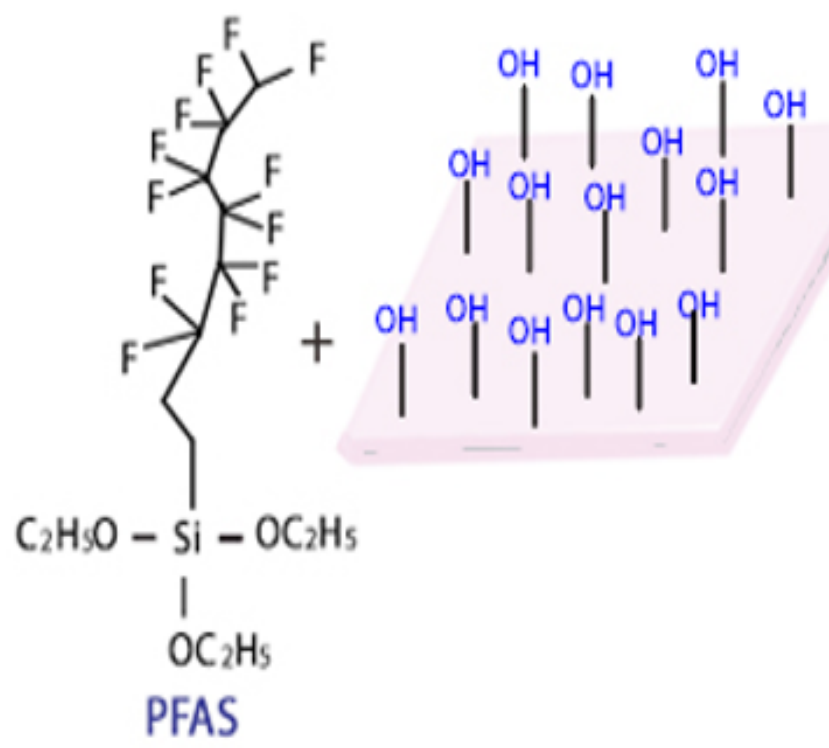

Condensation

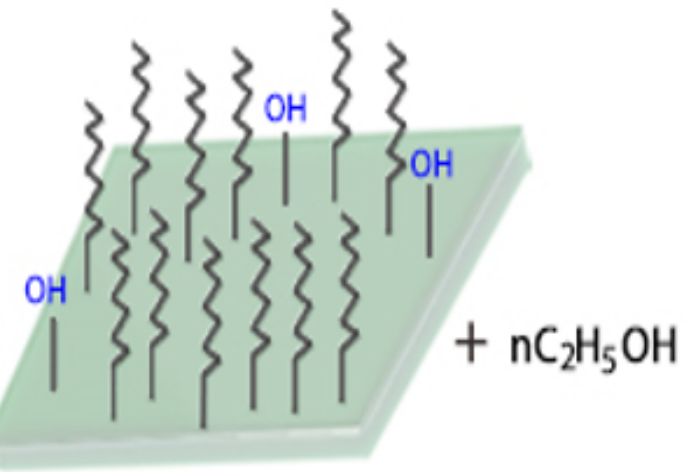

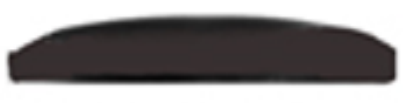

$\mathrm{CA}=20^{\circ}$
Hydrophobization

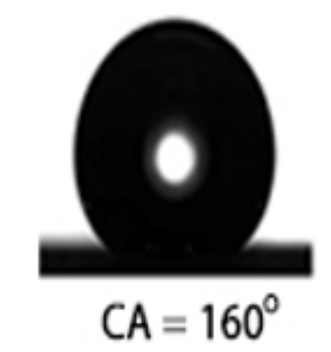


Figure 1

Scheme of the grafting process by PFAS compounds.

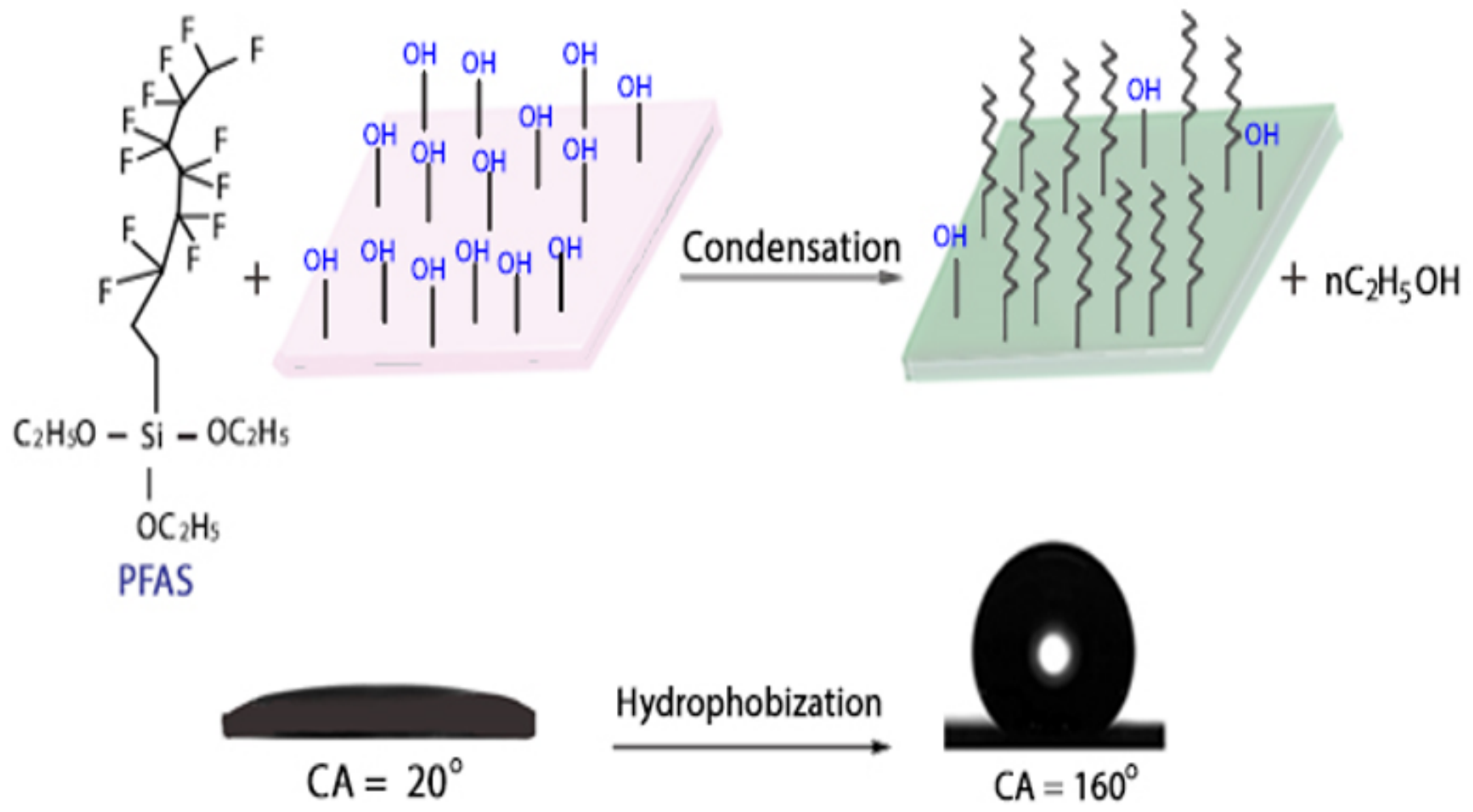

\section{Figure 1}

Scheme of the grafting process by PFAS compounds. 


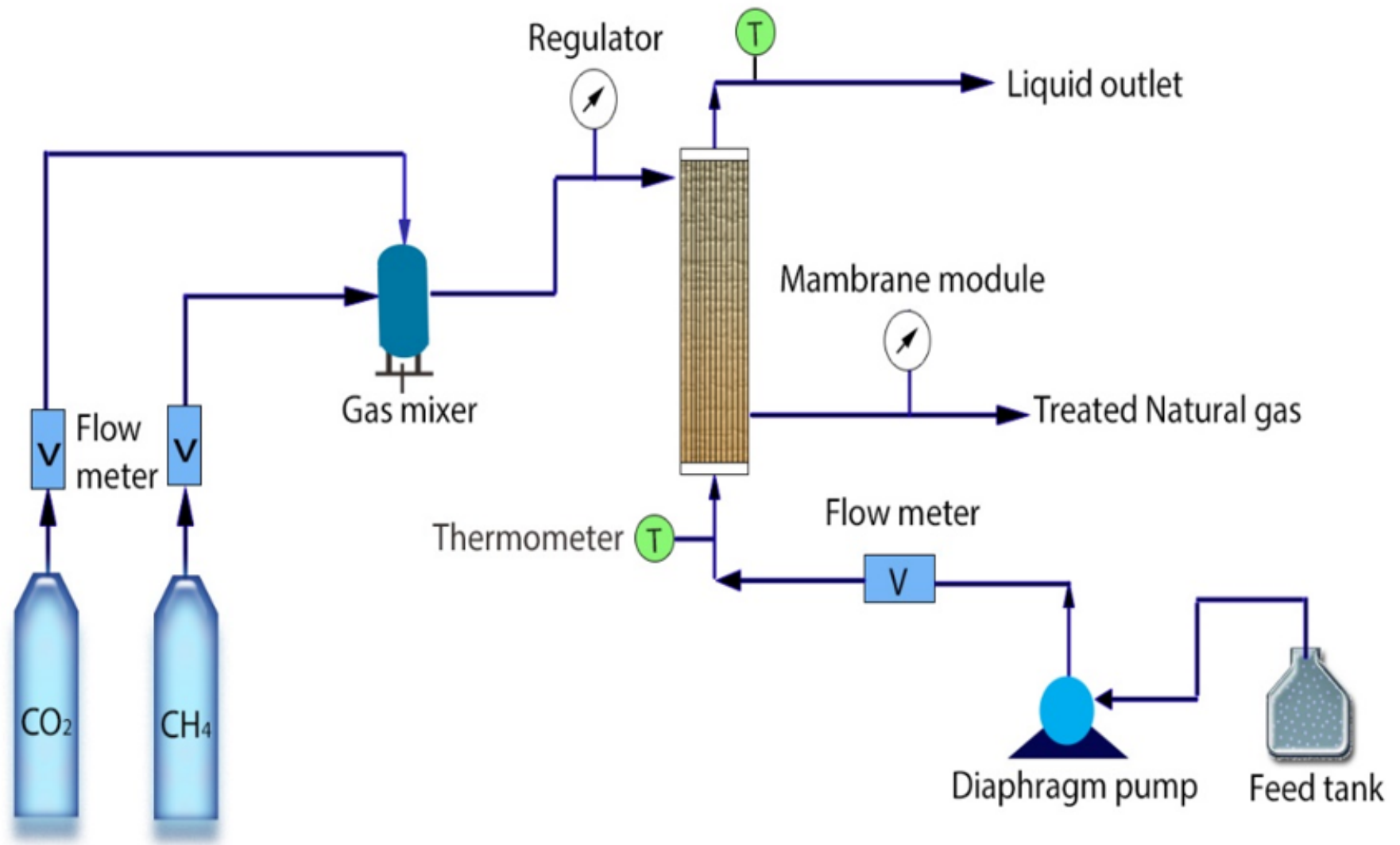

Figure 2

Schematic the integrated method by using a water absorber membrane contactor method to complete CO2 separation from natural gas. 


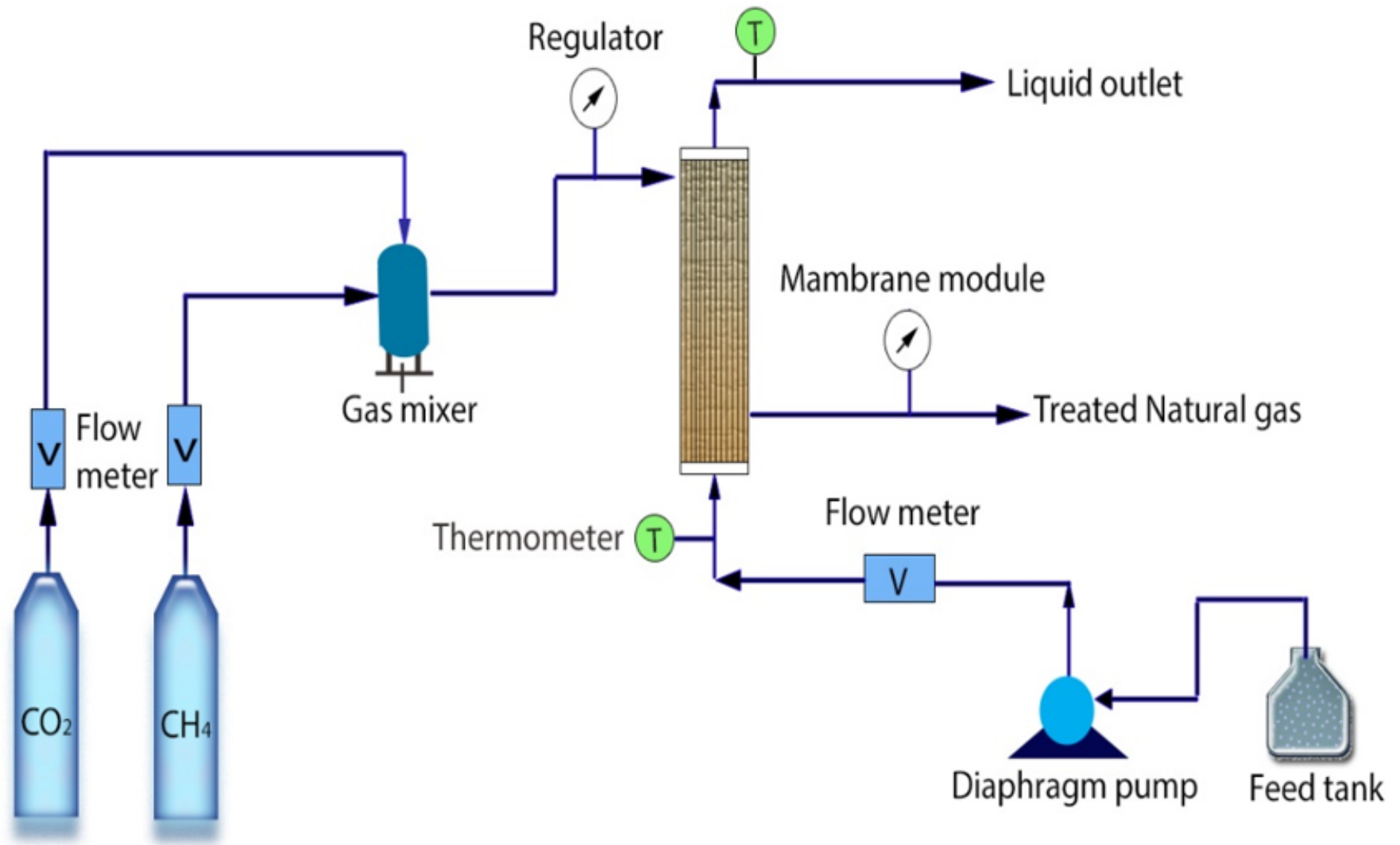

Figure 2

Schematic the integrated method by using a water absorber membrane contactor method to complete CO2 separation from natural gas. 


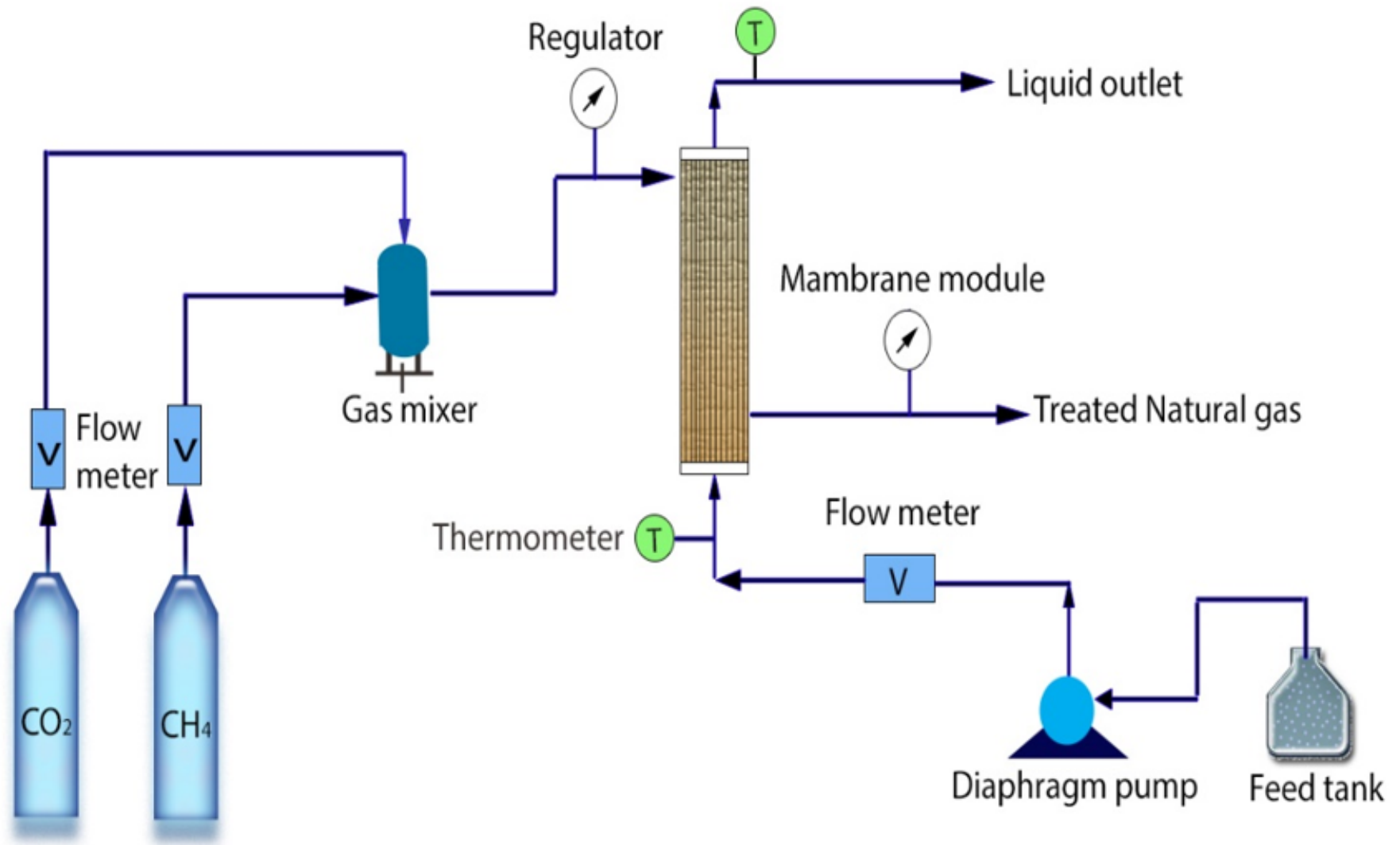

Figure 2

Schematic the integrated method by using a water absorber membrane contactor method to complete CO2 separation from natural gas. 


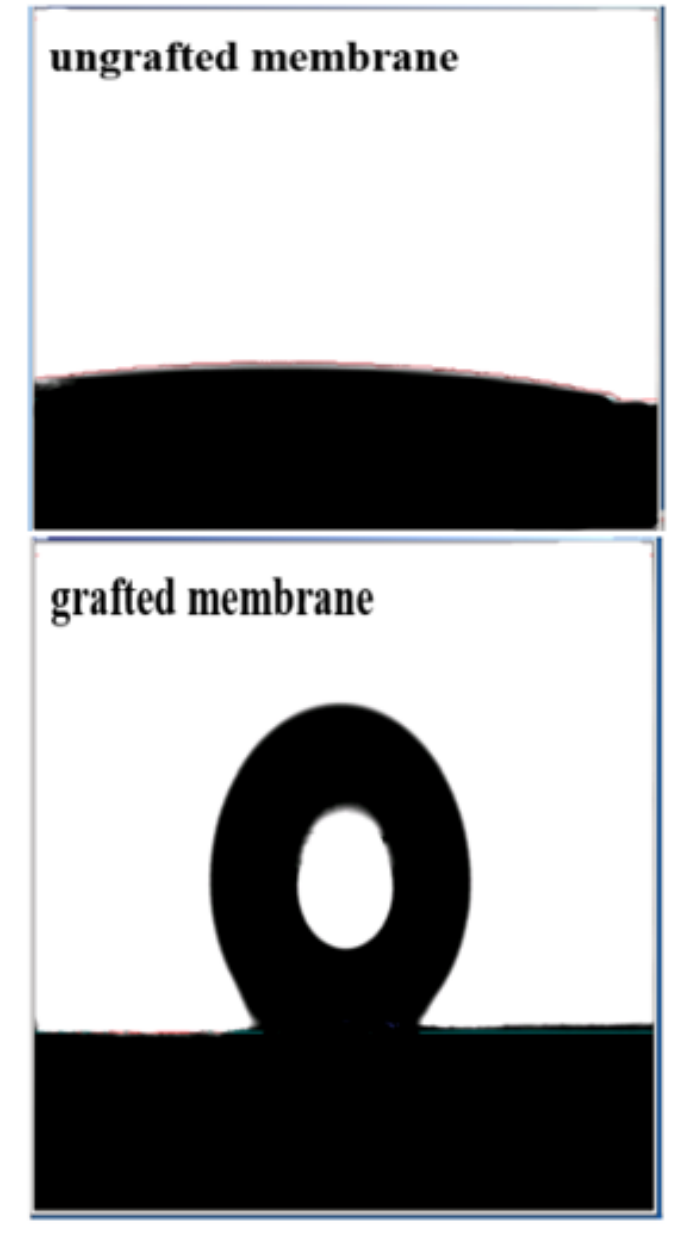

(a)

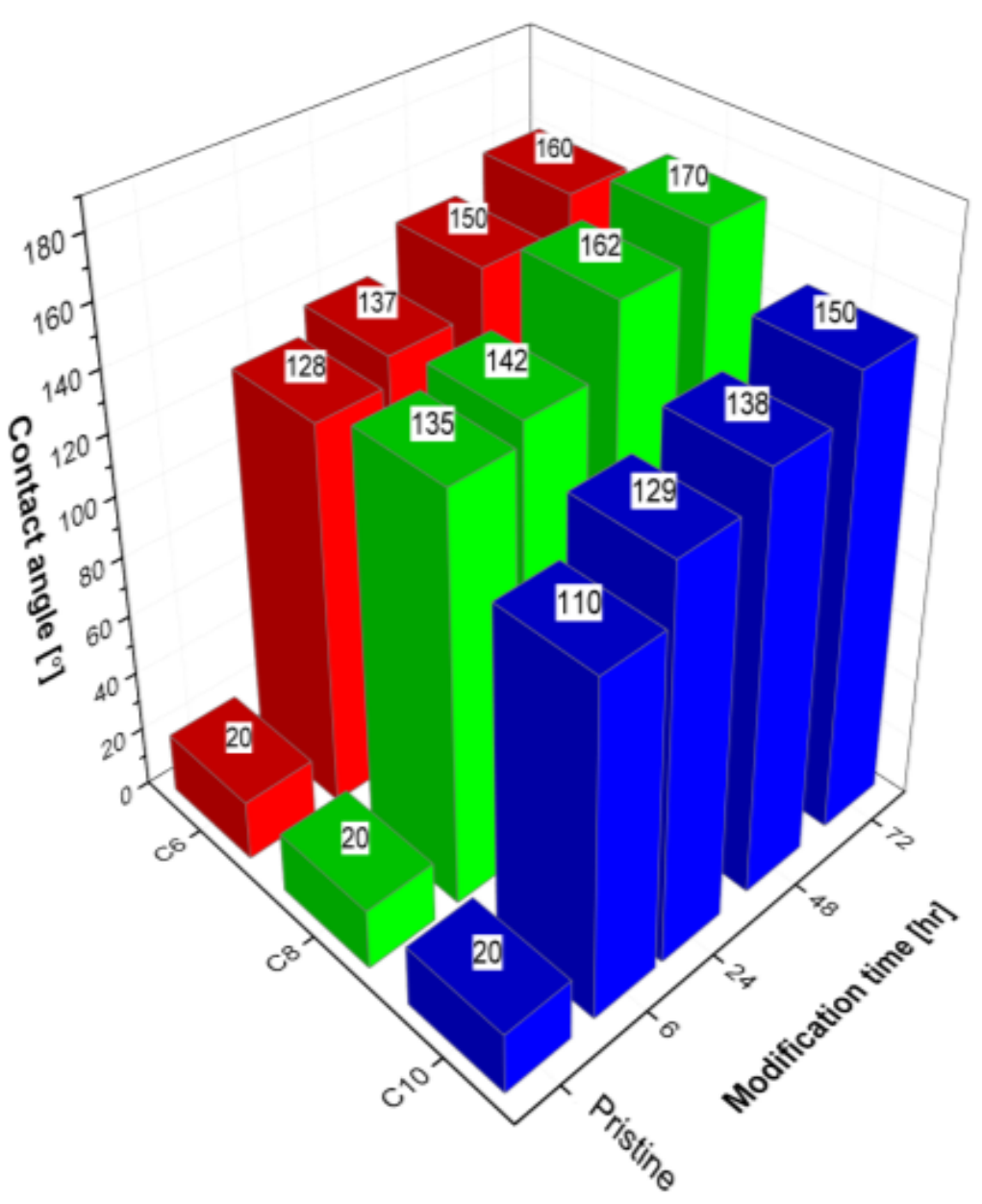

(b)

\section{Figure 3}

Contact angle for kaolin membrane (a) shape of water drop after and before grafting, the (b) value of contact angle at different times. 


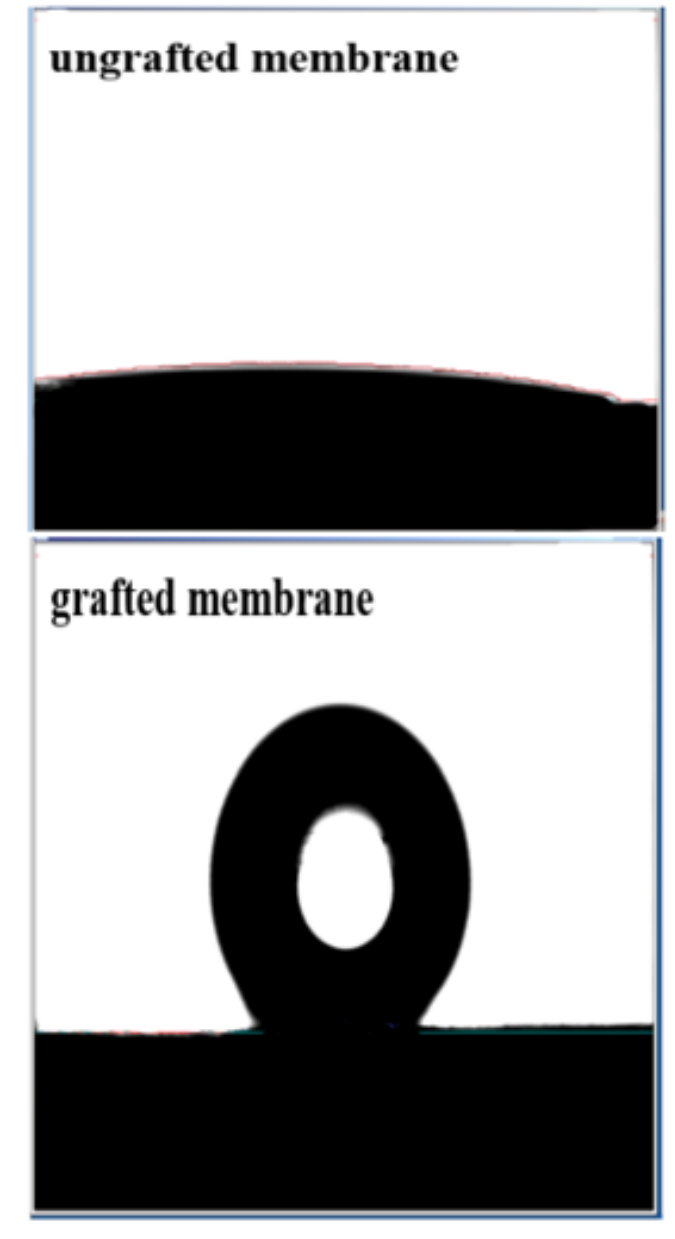

(a)

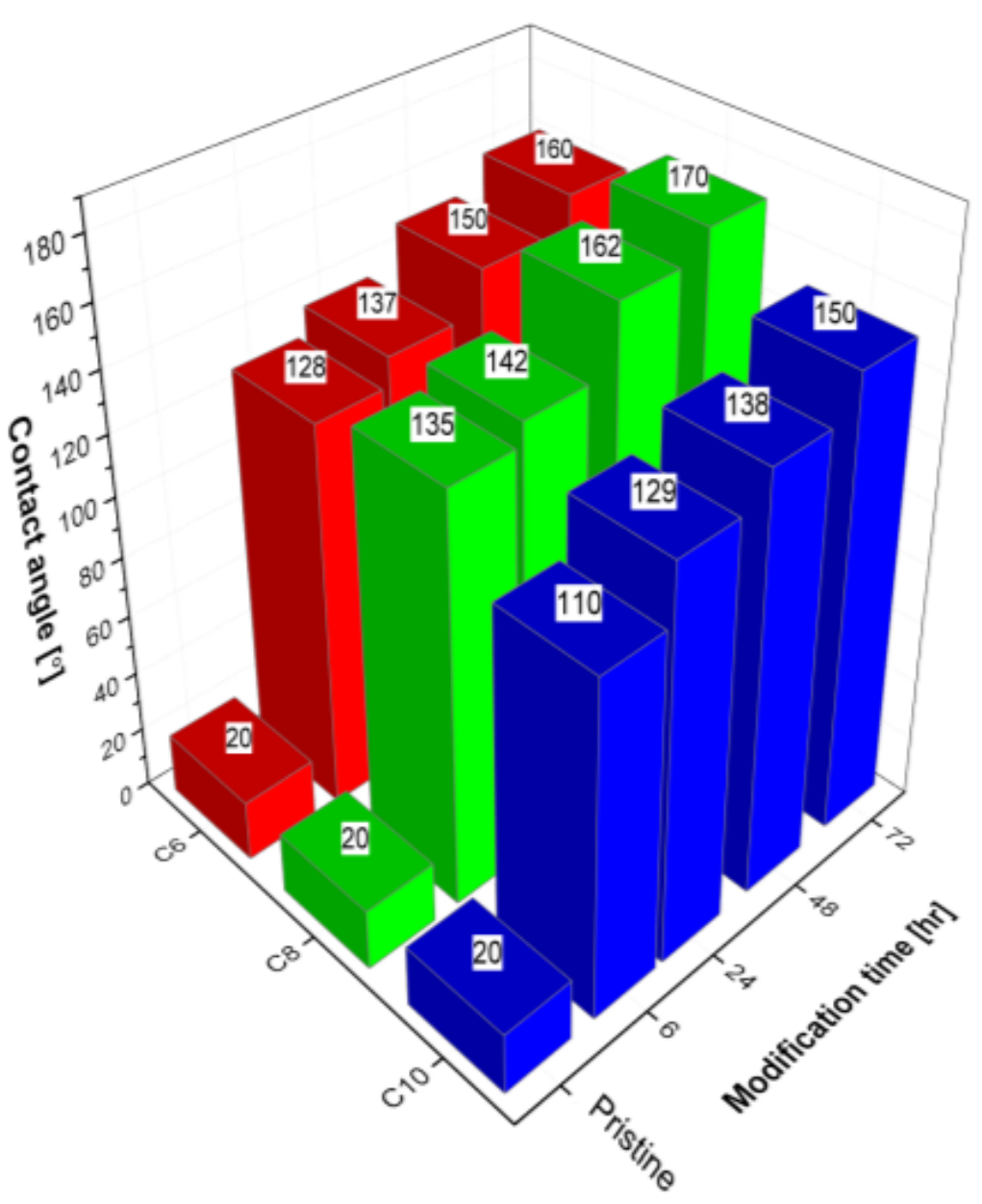

(b)

\section{Figure 3}

Contact angle for kaolin membrane (a) shape of water drop after and before grafting, the (b) value of contact angle at different times. 


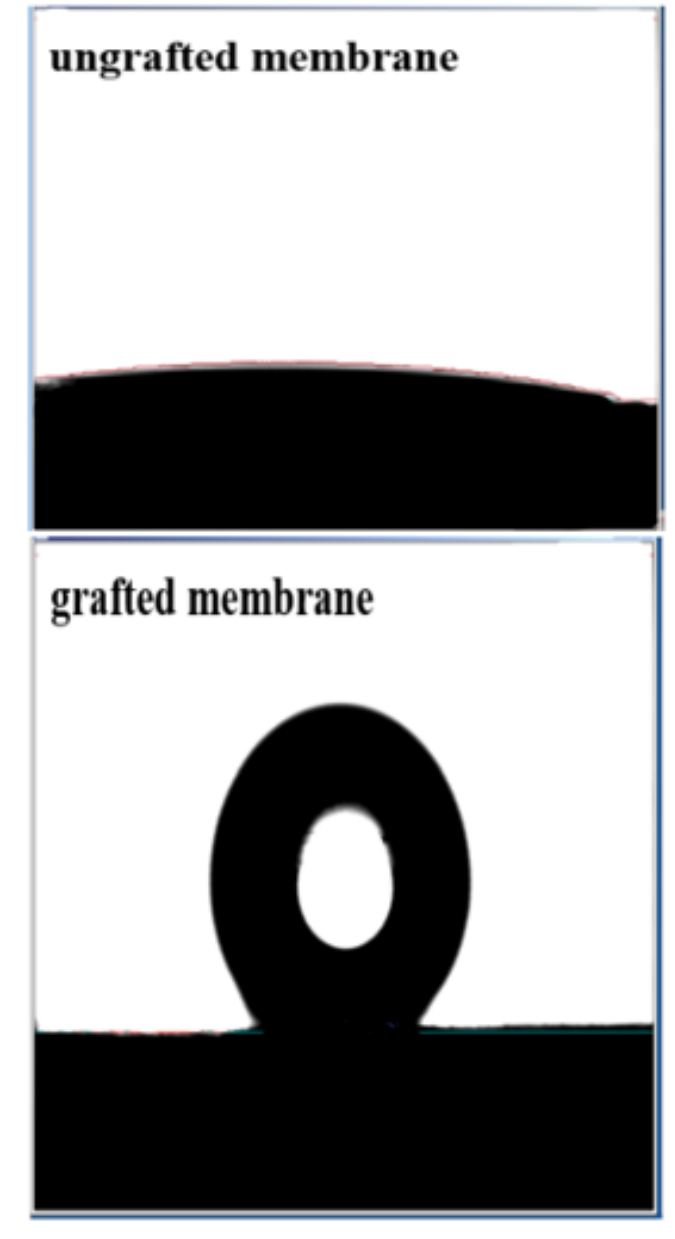

(a)

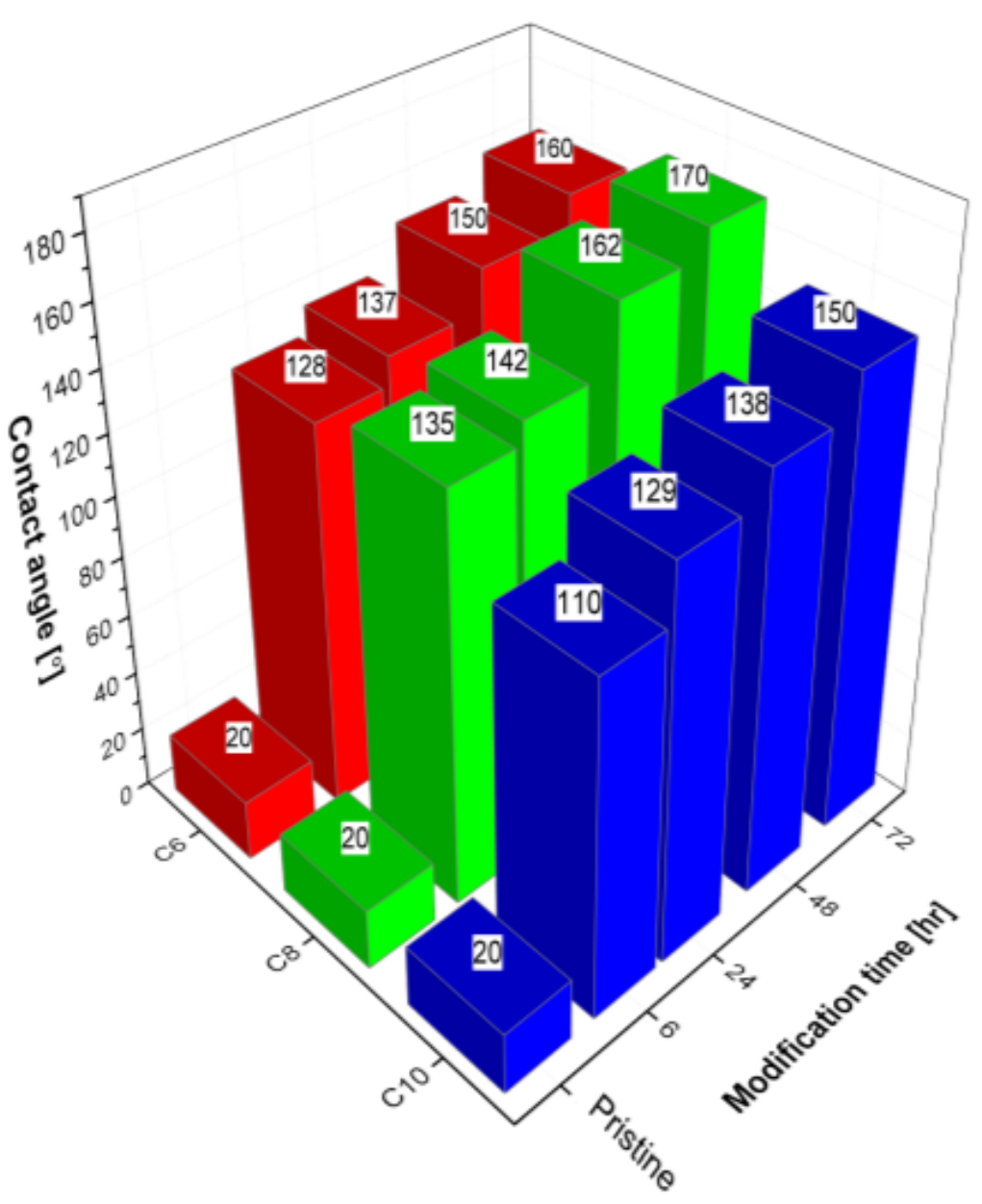

(b)

\section{Figure 3}

Contact angle for kaolin membrane (a) shape of water drop after and before grafting, the (b) value of contact angle at different times. 


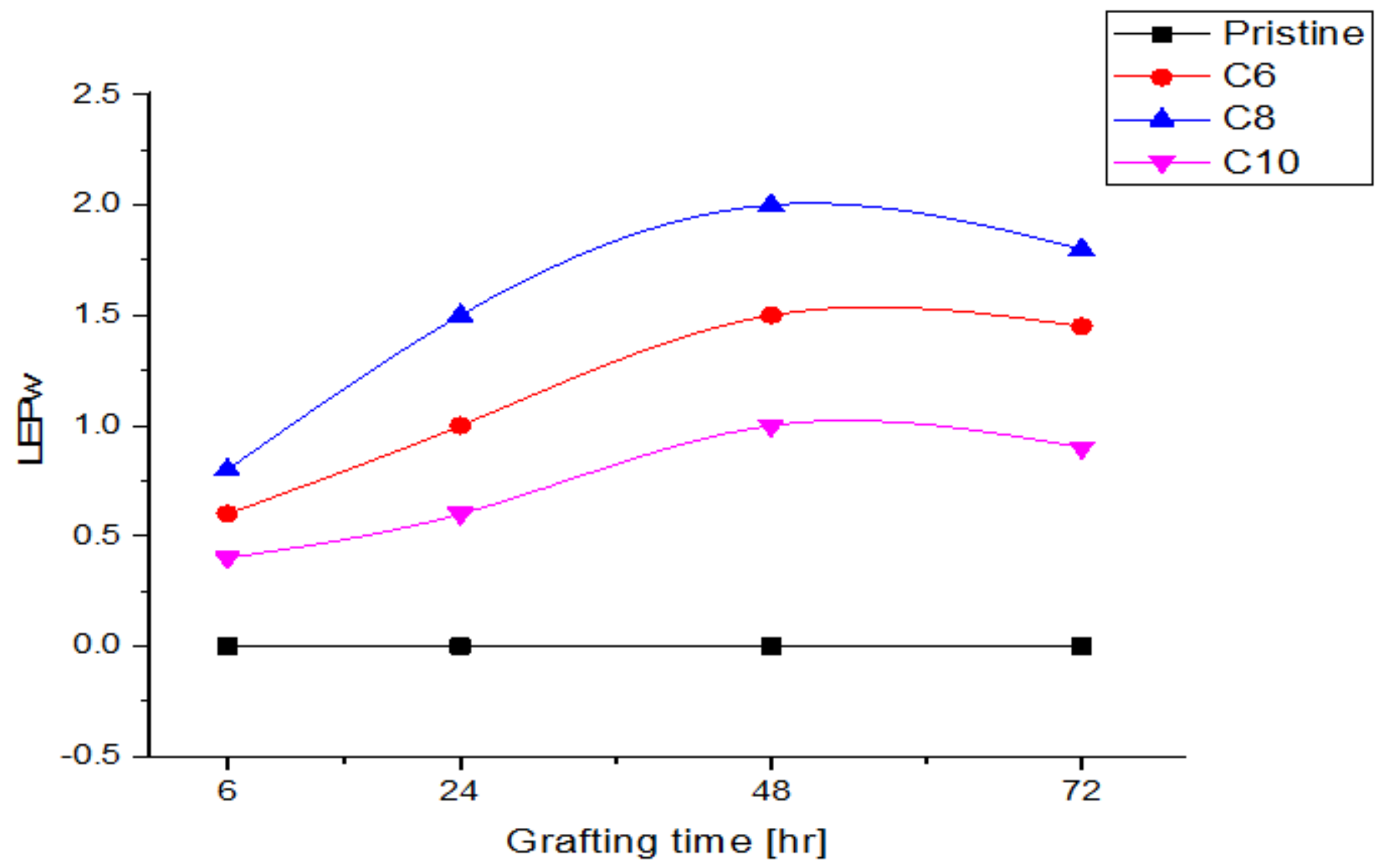

Figure 4

Liquid entry pressure of kaolin membrane water (LEPw) after grafting with three different forms of FAS. 


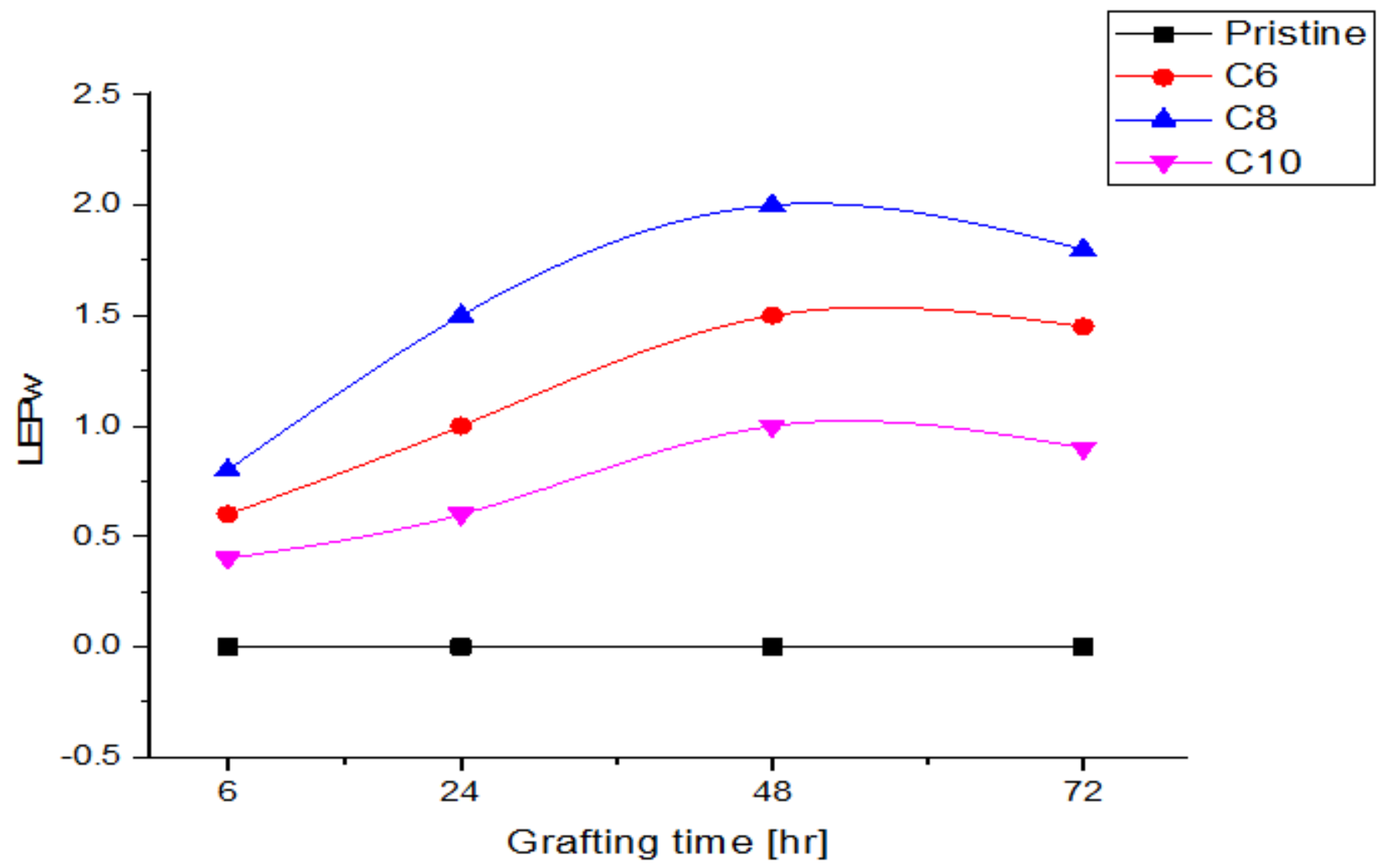

Figure 4

Liquid entry pressure of kaolin membrane water (LEPw) after grafting with three different forms of FAS. 


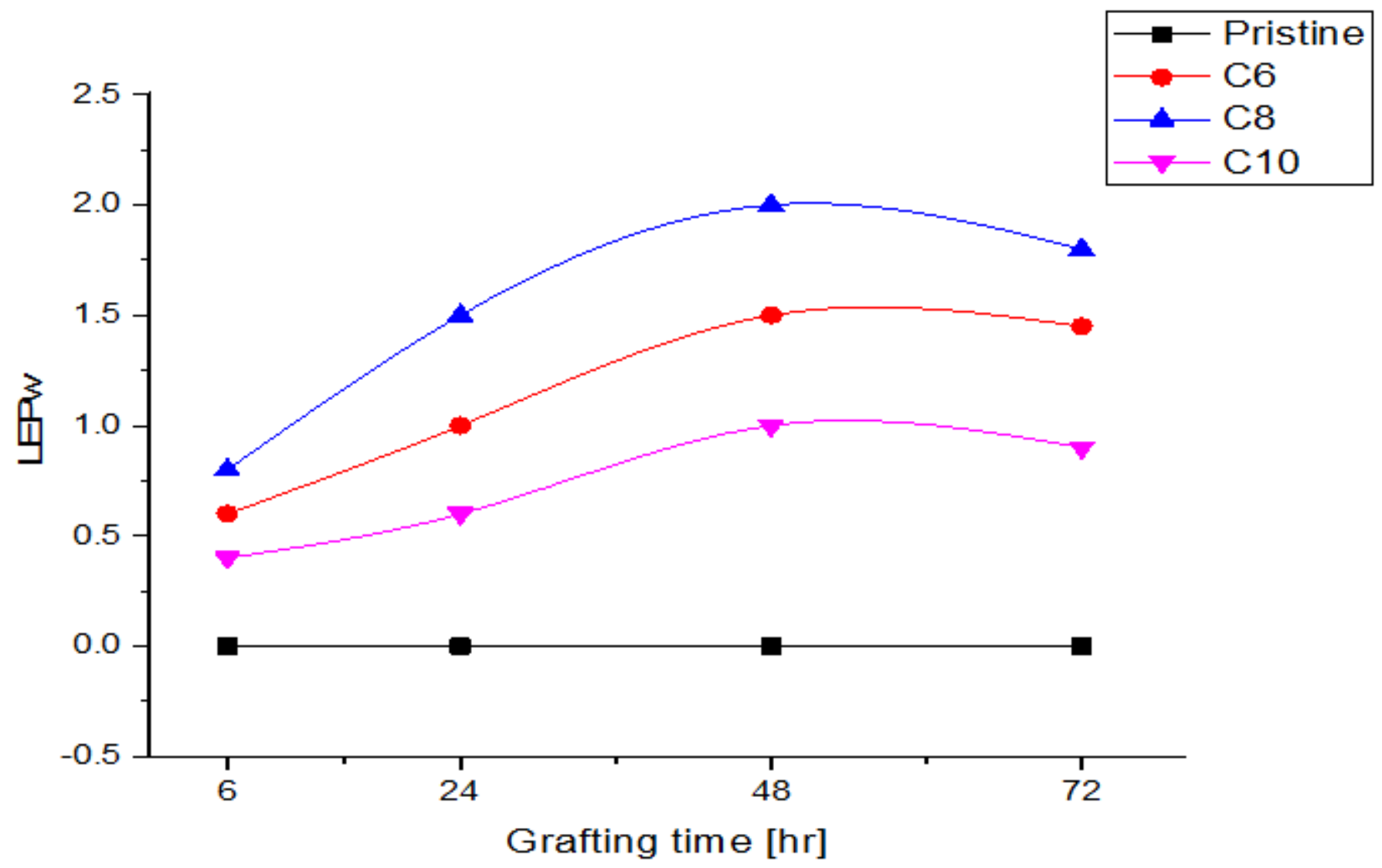

Figure 4

Liquid entry pressure of kaolin membrane water (LEPw) after grafting with three different forms of FAS. 

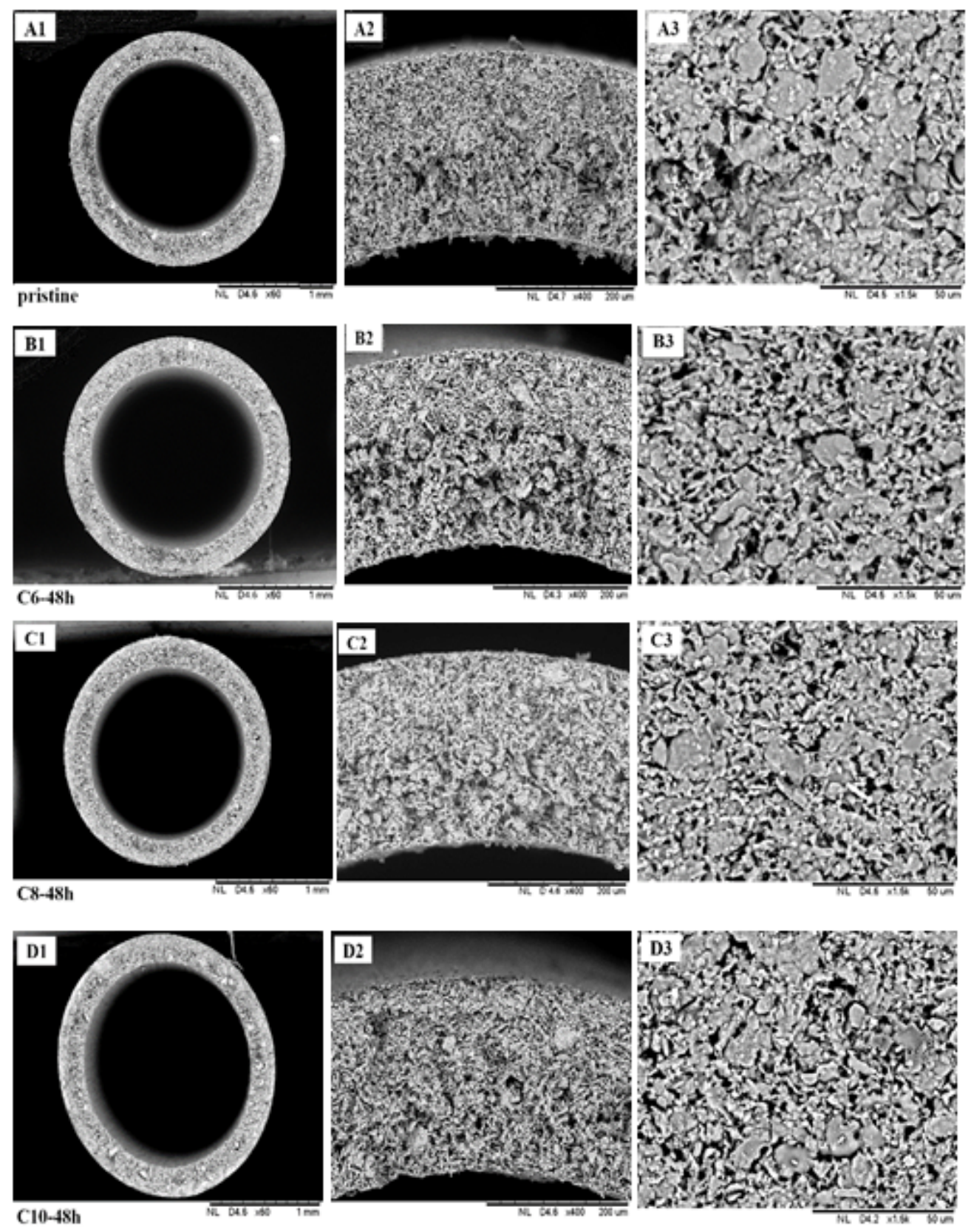

Figure 5

SEM images of (A) non-grafted and grafted kaolin hollow fibre with [(B) C6, (C) C8, (D) C10] at 48h, (1) cross-section; (2) Extensive cross-section; (3) outside surface. 

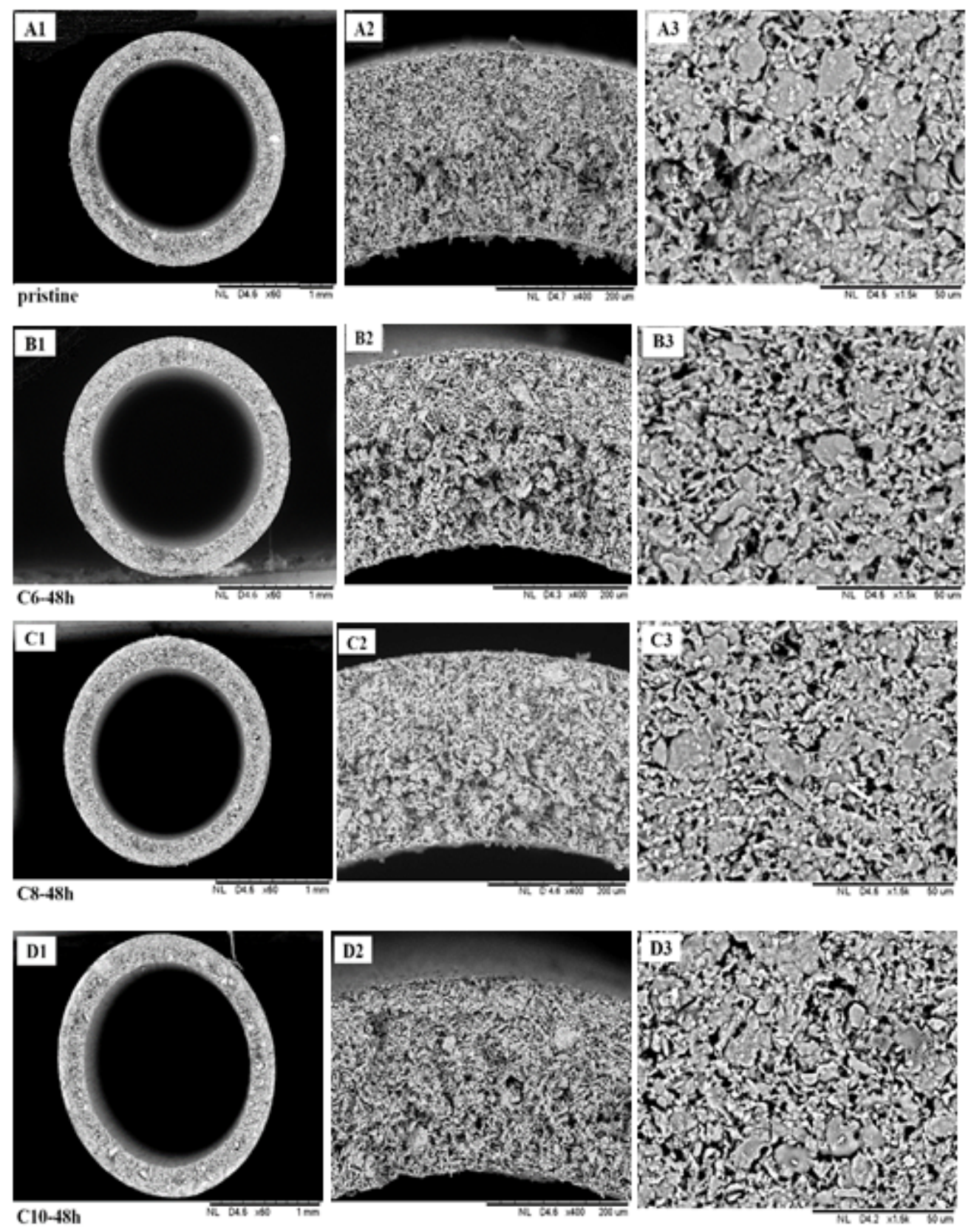

Figure 5

SEM images of (A) non-grafted and grafted kaolin hollow fibre with [(B) C6, (C) C8, (D) C10] at 48h, (1) cross-section; (2) Extensive cross-section; (3) outside surface. 

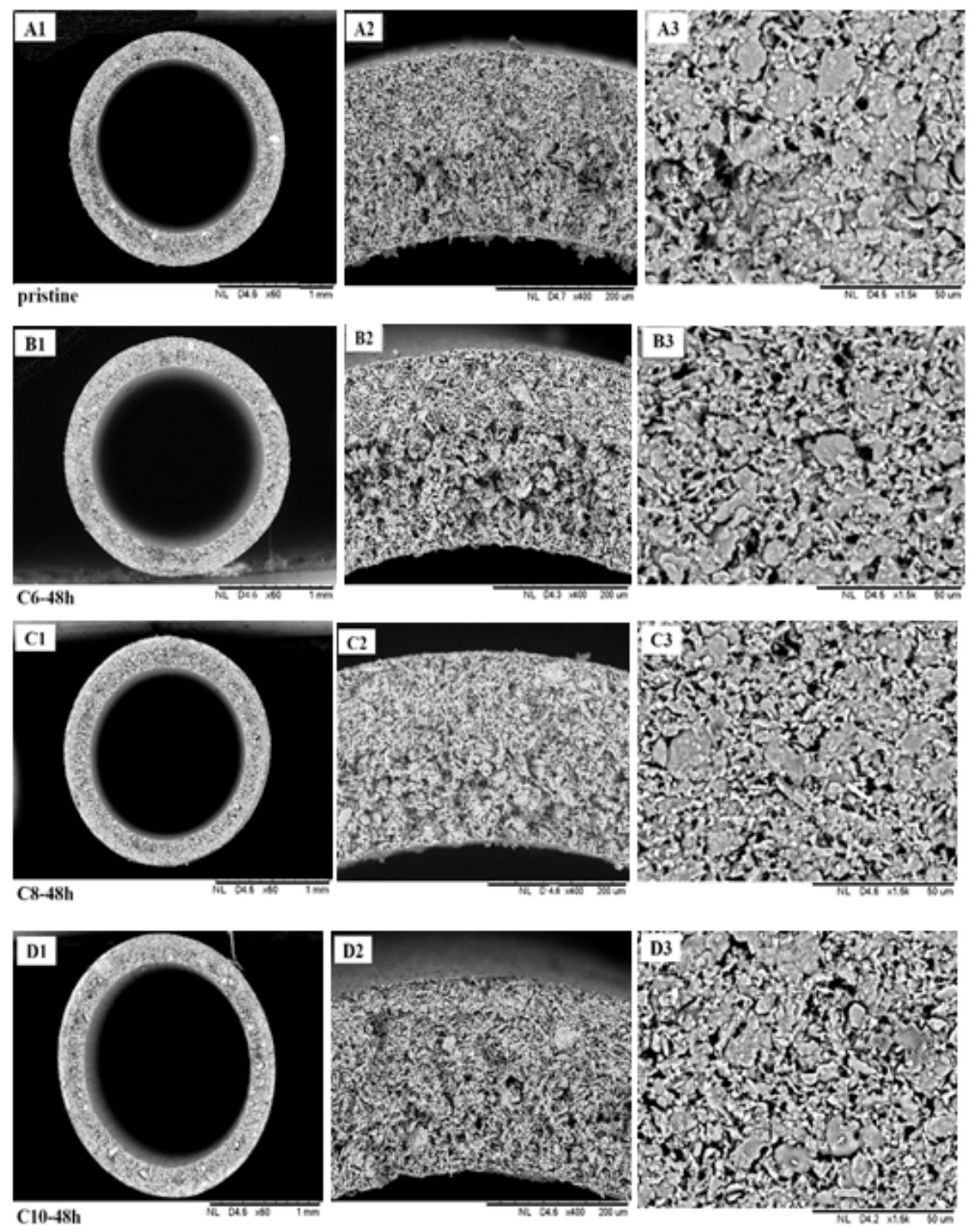

Figure 5

SEM images of (A) non-grafted and grafted kaolin hollow fibre with [(B) C6, (C) C8, (D) C10] at 48h, (1) cross-section; (2) Extensive cross-section; (3) outside surface. 


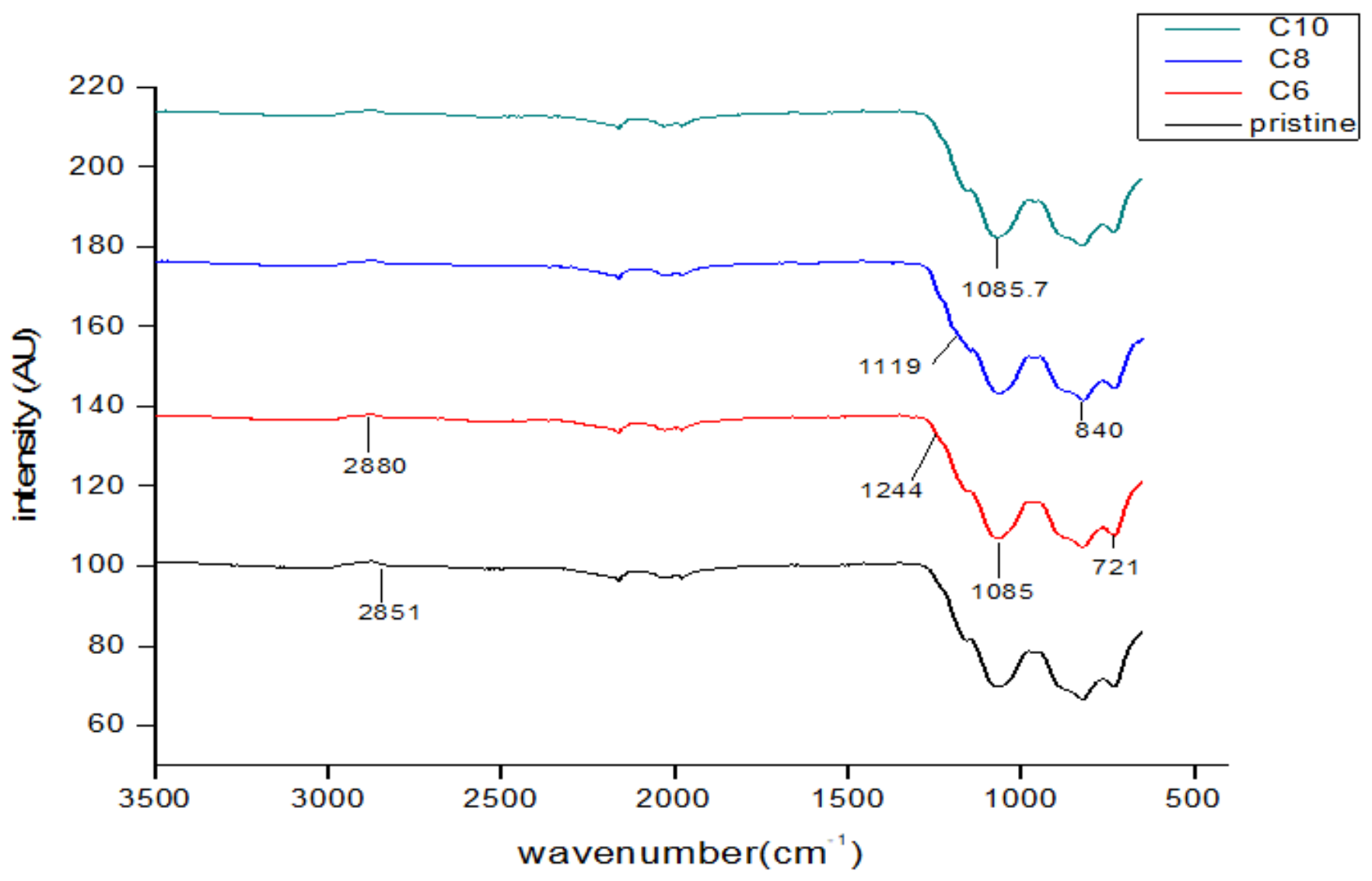

Figure 6

Kaolin hollow fibre spectra FT-IR before and after grafting with three FAS groups (C6, C8, and C10) at 48h. 


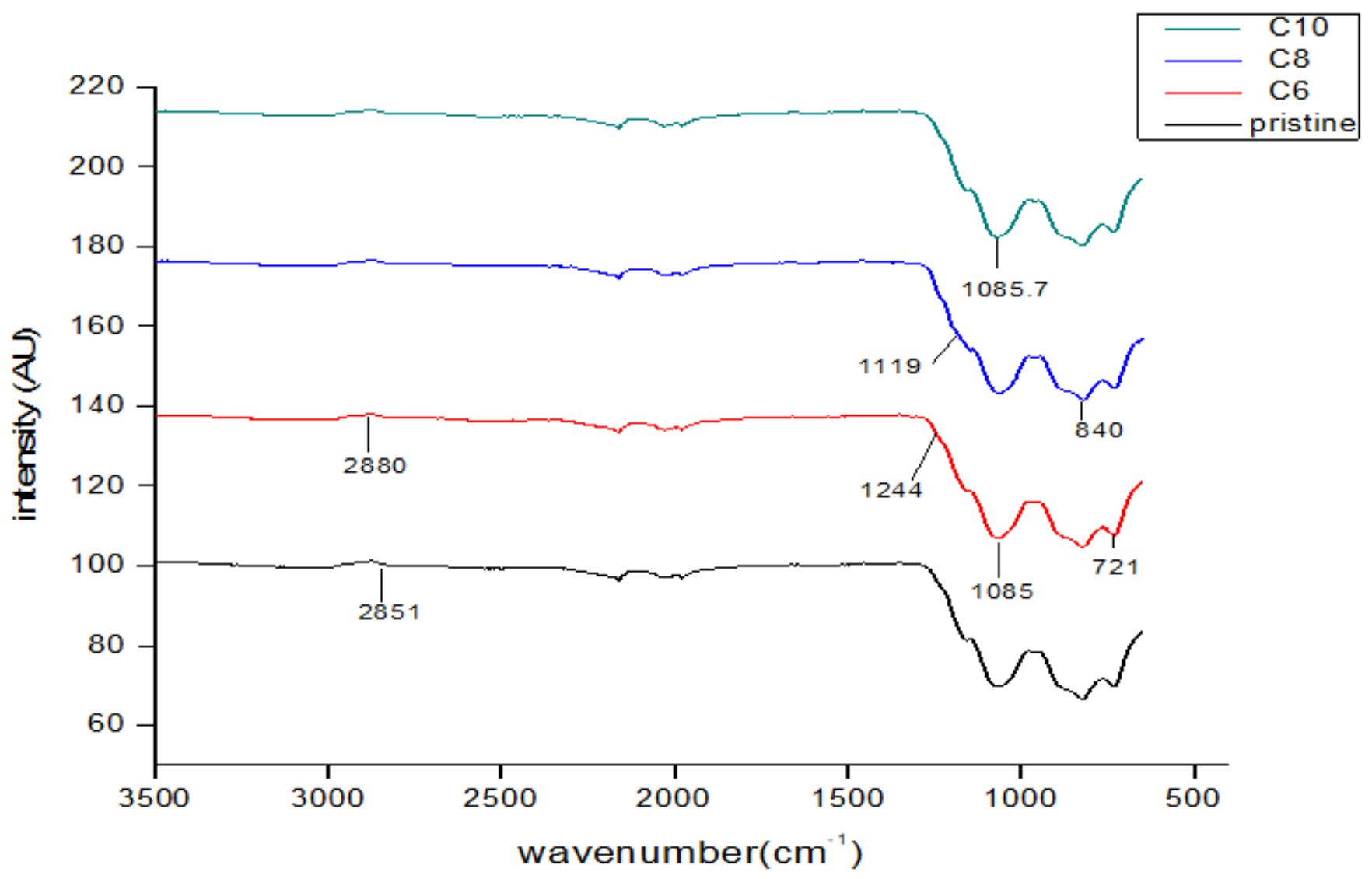

Figure 6

Kaolin hollow fibre spectra FT-IR before and after grafting with three FAS groups (C6, C8, and C10) at 48h. 


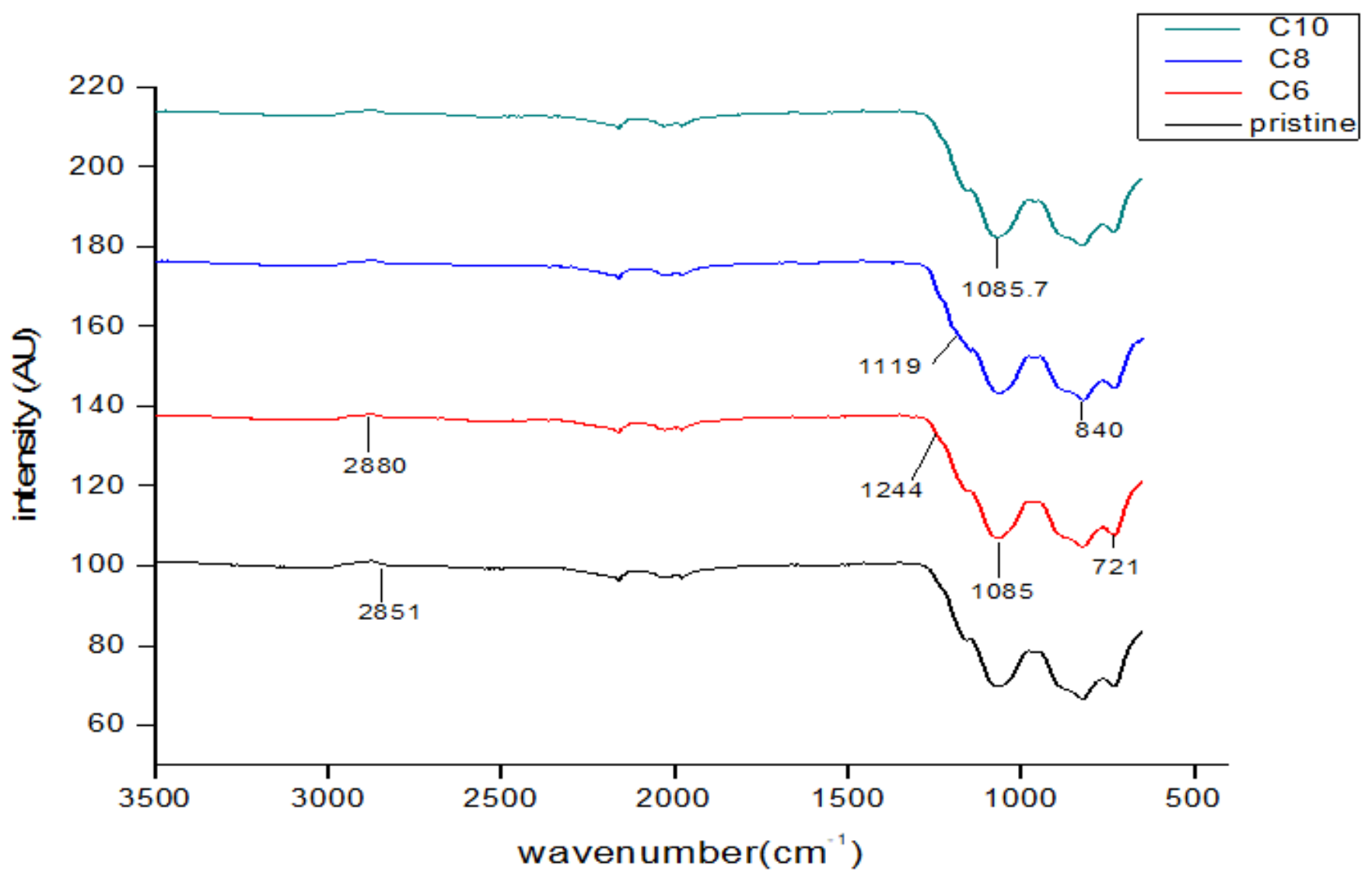

Figure 6

Kaolin hollow fibre spectra FT-IR before and after grafting with three FAS groups (C6, C8, and C10) at 48h. 


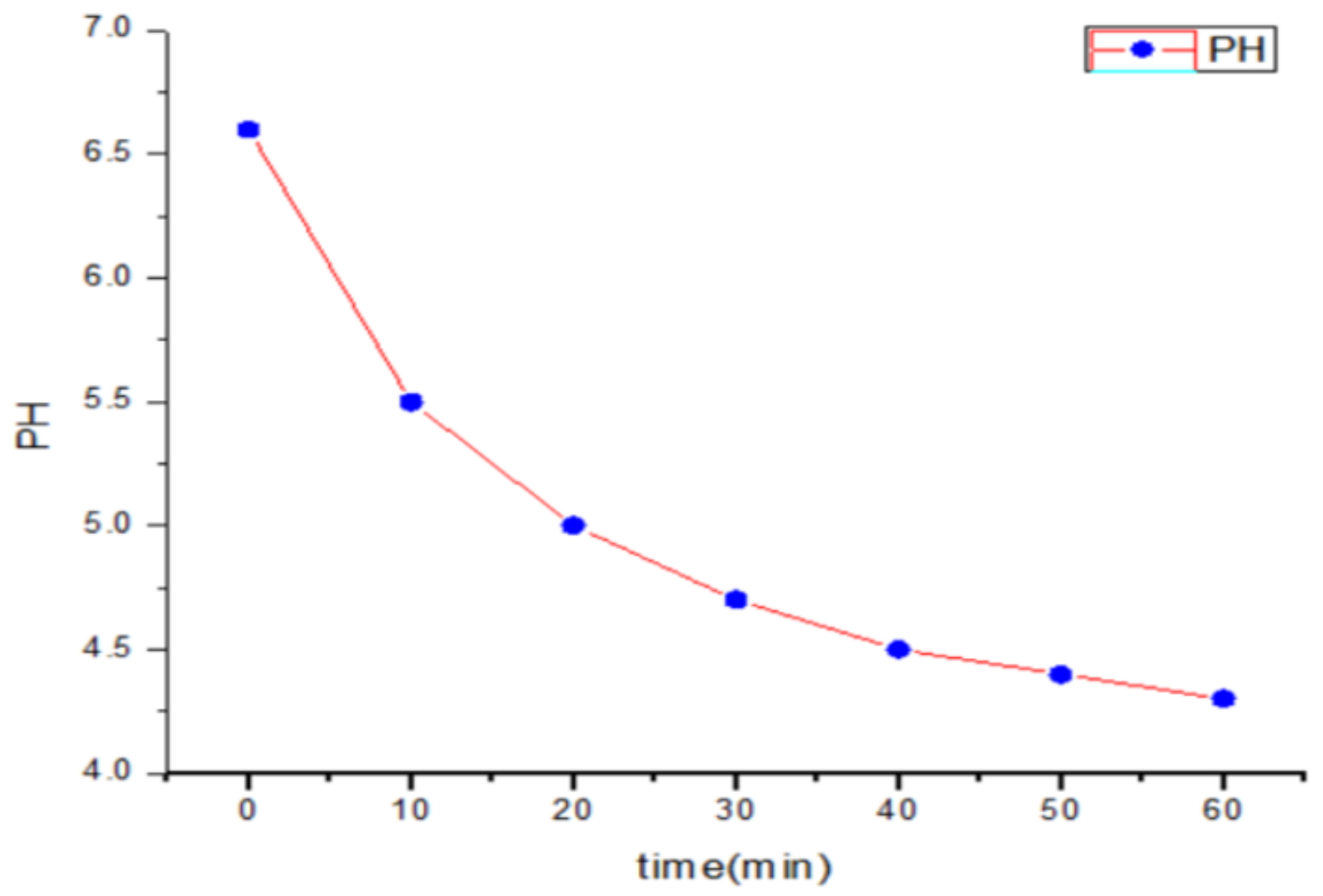

Figure 7

$\mathrm{pH}$ value against different periods for kaolin membrane grafted by C8. 


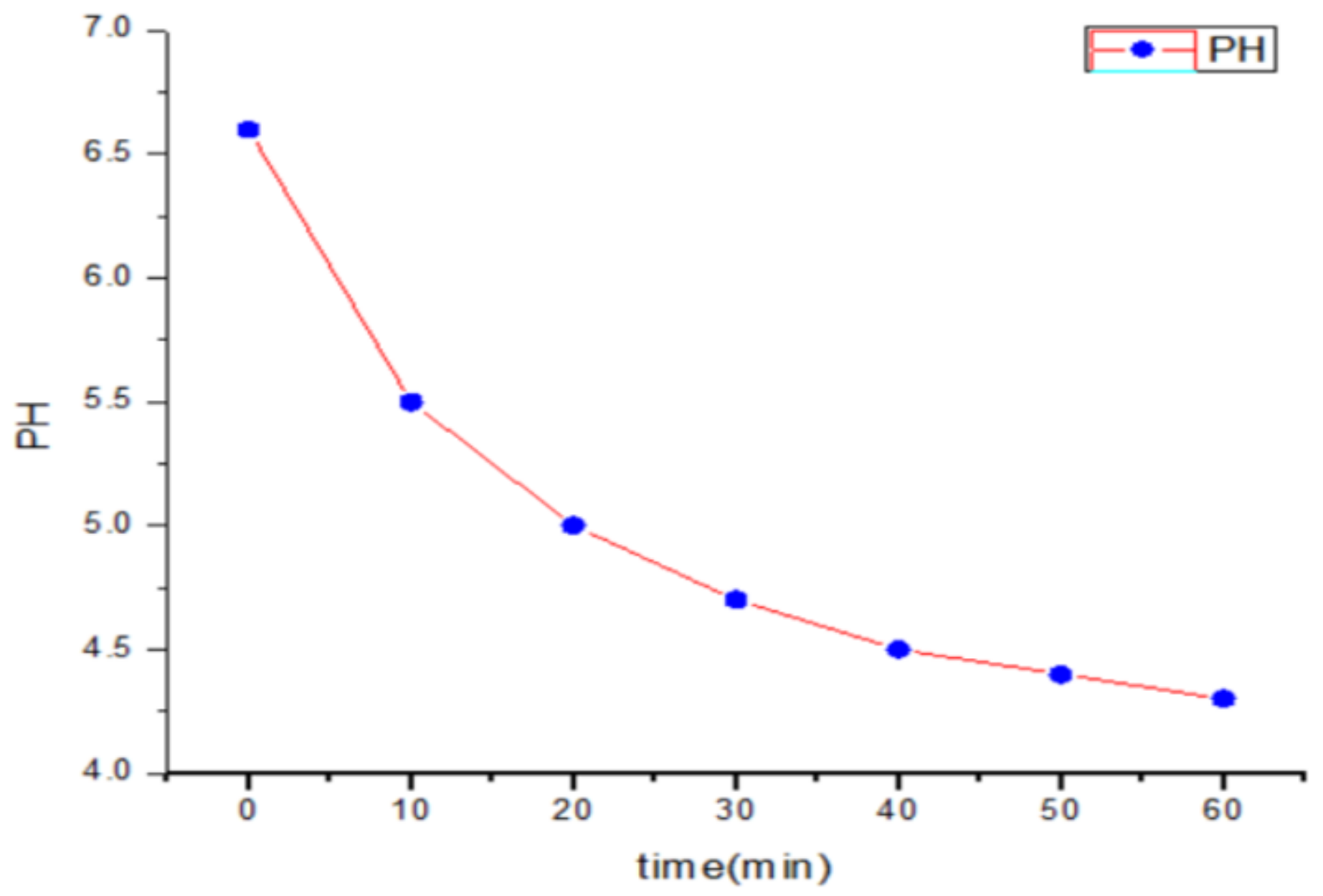

Figure 7

$\mathrm{pH}$ value against different periods for kaolin membrane grafted by C8. 


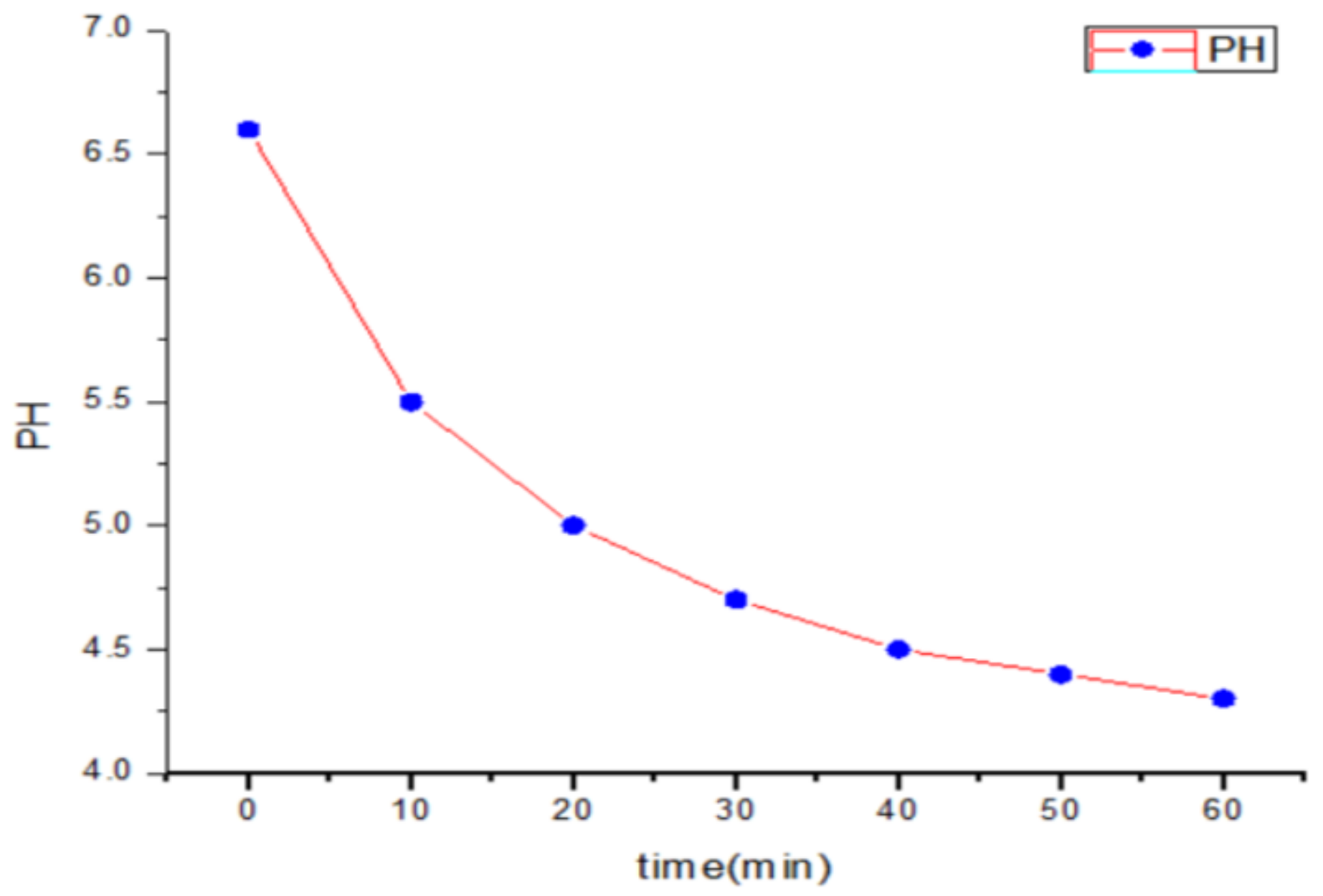

Figure 7

$\mathrm{pH}$ value against different periods for kaolin membrane grafted by C8. 